\title{
Joint Pricing and Inventory Replenishment Decisions with Returns and Expediting under Reference Price Effects
}

\author{
Yuan Li $(\mathbb{D})^{1,2}$ and Yumei Hou $\left.{ }^{1}\right)^{1}$ \\ ${ }^{1}$ School of Economics and Management, Yanshan University, Qinhuangdao, Heibei Province 066004, China \\ ${ }^{2}$ College of Mathematics, Inner Mongolia University for the Nationalities, Tongliao, \\ The Inner Mongolia Autonomous Region 028000, China
}

Correspondence should be addressed to Yumei Hou; hdzw_wei@163.com

Received 3 January 2019; Revised 4 April 2019; Accepted 14 April 2019; Published 24 April 2019

Academic Editor: Konstantina Skouri

Copyright (C) 2019 Yuan Li and Yumei Hou. This is an open access article distributed under the Creative Commons Attribution License, which permits unrestricted use, distribution, and reproduction in any medium, provided the original work is properly cited.

\begin{abstract}
This paper considers a single-item joint pricing and inventory replenishment problem under reference price effects in consecutive $T$ periods. Demands in consecutive periods are sensitive to price and reference price with general demand distribution. At the end of each period, after the demand realization, a firm can return excess stocks to a supplier or place an expediting order to reduce the loss by shortage. Unfilled demands are fully backlogged. In order to maximize the total expected discounted profit with reference price effects the optimal pricing and inventory replenishment policies for regular order and the inventory adjustment decisions for returning/expediting are derived. The optimal replenishment policy for regular order is a base-stock policy, the optimal pricing policy is a base-stock-list-price policy, and the optimal policy for returning/expediting inventory adjustment follows a dualthreshold policy. Furthermore, the analysis of the operational impacts (from the perspective of adding returning/expediting and reference price effects, respectively) is researched. Numerical results also show that considering both returning/expediting and reference price effects is more profitable than considering only one of them.
\end{abstract}

\section{Introduction}

Reference price, as the cognitive price of customers, is formed through the customers' repeated purchasing experiences. Reference price was first derived from the adaptation level [1], and its definition was still vague. Since then, prospects theory [2] and behavioral sciences [3] elaborated the reference price in detail; they indicated that customers will remember past prices when they repeat the purchase of the commodity. Especially, the growing information transparency with the advent of the Internet has made it more convenient for customers to learn the historical price information of a commodity. Customers often develop their own "fair price" which is named as the reference price after observing past prices of a commodity. If the current sales price is lower (higher) than the reference price, customers think that price is a gain (loss) price. Hence they are more likely (less inclined) to make the purchase. This phenomenon is usually referred to as the reference price effects. Customers are called loss averse (loss neutral) if customers perceived losses are more sensitive than their perceived gains. Otherwise, they are called loss seeking. Many firms are aware of the importance of this effect and take it into account to maximize their profits. For example, Alibaba who is the largest Internet company in China and is also the second largest Internet company in the world sold 213.5 billion yuan during "double 11" in 2018, which exceeded the record of 168.2 billion yuan in 2017. In addition, the number of express delivery during the "double 11" period exceeded 1 billion. These show that more and more customers are willing to choose to add the desired commodities to the "shopping cart" firstly and wait until the "double 11" day to pay for them at a promotion (lower) price. Actually, this phenomenon of "double 11" is a typical strategic consumer behavior. When people encounter the commodity they need they will no longer impulsively buy it immediately. Instead, they will wait the sales price reasonably comparing to the reference price before purchasing. There are similar examples in the market which are sales for electronic, clothing, and 
other tidal commodities [4]. Hence, the reference price effect has an important impact on demand and therefore becomes an indispensable part of firms' decision making.

With the economic globalization and the increasingly fierce market competition, improving supply chain performance becomes more crucial for firms and the revenue management theory in combining dynamic pricing and inventory control methods have significant effects on the improving of supply chain performance. Therefore, in making decisions, many firms not only consider the impact of reference price effects on pricing strategies, but also the impact on inventory strategies simultaneously, such as Amazon, Dell, and WalMart [5]. Besides, the existence of strategic consumers makes demand difficult to accurately estimate. In order to match supplies with demands in a cost-effective way, firms require their suppliers to provide more flexibility for the replenishment process, such as the opportunities of return and expediting. One typical example is the eHub system launched by Cisco in 2001 [6]. It is a trading e-marketplace that provides a platform for the planning and executing tasks across the company's extended manufacturing supply chain. By eHub, Cisco connects with its suppliers to build up a flexible/agile supply channel, where Cisco is allowed to return the excess stock and to place expediting orders. In this way, Cisco can reduce the waste in inventory and increase the speed to response to customers' needs. Similar operational practice is also observed in Toyota and Motorola [7, 8]. As a result, the impact of flexibility for the replenishment on the operational efficiency for firms is also a very noteworthy aspect. It is precisely because the reference price and strategy customers have great effects on firms' pricing and ordering operations; therefore, it is essential to investigate the joint pricing and flexible ordering strategies with considering the effects of the reference price.

As a matter of fact, the inventory strategies (including regular and returning/expediting inventory) and reference price interact with each other in a sales period. So it is necessary to study how the reference price affects both the regular and returning/expediting replenishment policies. However, to the best of our knowledge, the reference price effect has not been considered in the study of flexibility for the replenishment in recent years (see, for example, [9-13]). Besides, most recent research on coordinating pricing and inventory control problem with reference price effects has focused on the ordering policy for regular inventory (see, for example, [14-17]). Little attention has been paid to the flexibility for the replenishment, such as returns and expediting [9]. These motivate us to do the explore in this aspect in our paper.

The strategy customers' behavior has great impact on the joint decisions on pricing and inventory by demand. In a single-item, periodic-review model, demands in consecutive periods are price and reference price sensitive random variables. We study the joint decision problem on determining pricing and inventory control strategies with returns and expediting under reference price effects. When introducing returning/expediting decisions, the following technical problems will arise: (1) whether the supermodularity of the value function can be guaranteed when the decision variable of returning/expediting is added; (2) whether the regular replenishment strategy established in previous literature, such as Güler et al. [14, 15] and Chen et al. [17], is still the basestock policy; (3) how the reference price impacts the returning/expediting decision making; (4) do firms benefit from the simultaneous consideration of returning/expediting and reference price. To answer these research questions, this paper develops a dynamic programming model to find the optimal dynamic policies that determine the pricing and inventory replenishment for regular order and inventory adjustment decisions for returning/expediting adjustment under reference price effects in each period so that the total expected discounted profit is maximized. For a very general stochastic demand function, we show that the optimal inventory replenishment and optimal pricing policies for regular order are base-stock policy and base-stock-list-price policy, respectively. The optimal policy for returning/expediting inventory adjustment follows a dual-threshold policy. The preservation of supermodularity of value function enables us to discuss the effects of reference price on returning/expediting. We further study the operational impacts of returning/expediting under reference price effects by comparing with the model proposed by Chen et al. [17] and Zhu [9], respectively.

The remainder of this paper is organized as follows. Section 2 reviews related literature. We present the finite period model with stochastic dynamic programming in Section 3 and characterize the optimal policies in Section 4. The infinite planning horizon problem is discussed in Section 5. Section 6 investigates the operational impacts from the perspective of adding returning/expediting and reference price effects, respectively. Numerical results are represented in Section 7. Section 8 concludes our paper.

\section{Literature Review}

The work is mainly related to two streams of literature: (i) inventory models with supply flexibility and (ii) joint pricing and inventory control under reference price effects.

In the literature on inventory models with supply flexibility, the earliest studies on this stream can be traced back to the late 1980s and the early 1990s. Eppen and Iyer [18] study a special form of the quantity flexibility contract, which allows the retailer to return a portion of its purchase to the supplier. Henig et al. [19] consider a minimum ordering quantity contract under which the firm decides whether to order the prefixed contract amount or order more than this amount at the beginning of each period, but an incremental cost will be charged for the excess amount ordered. They show that the optimal policy is a modified order-up-to policy under the assumption that the demands are independent and identically distributed. Further, the optimal policies are threshold type. Tsay and Lovejoy [20] extend the replenishment decision problems to a three-stage setting where the authors use a heuristic approach to transform the original stochastic problem into the deterministic problem that can be solved more easily. Sethi et al. [21] study the impact of forecast quality and the level of flexibility by quantity flexibility contract on the ordering decisions. Ben-Tal et al. [22] apply robust optimization to analyze the replenishment decisions under 
the quantity flexibility contract. Feinberg and Lewis [23] consider a broader problem, where in addition to increasing inventory or disposing of it, the manager can borrow or store some inventory for one period. They show that the optimal inventory policies depend on four thresholds. Yin and Rajaram [24] consider the emergency ordering model and prove the optimality of state-dependent $(s, S, p)$ policy for a class of Markovian demand. Lian and Deshmukh [25] use a frozen fence to restrict any change in the next one or more periods, penalty costs to discourage excessive modifications in other periods, and price discount to boost advanced orders. Fu et al. [26] analyze the effects of regular replenishment and expediting on the lead time from the viewpoint of inventory cost minimization. Chen et al. [27] use heuristic algorithms to derive the optimality of complex inventory systems based on the emergency ordering model of cost-price changes. Zhu [9] studies the pricing and inventory strategy with return and expediting and shows that the optimal inventory policy is a modified base-stock policy, the optimal pricing policy is a modified base-stock-list-price policy, and the optimal policy for inventory adjustment follows a dual-threshold policy. Fu et al. [10] consider the newsvendor problem with multiple options of expediting. Zhou and Chao [11] consider a periodic-review inventory system with regular and expedited supply modes, they show that the optimal inventory policy is determined by two state-independent thresholds, one for each supply mode, and the optimal price follows a list-price policy. Roni et al. [12] develop a stochastic inventory model based on a hybrid inventory policy with both regular and emergency orders responding to regular and surge demands. Li et al. [13] study a quantity flexibility contract that the retailer commits an amount of quantity of newly developed commodities, and in return the manufacturer allows the retailer to adjust the order quantities of the commitment quantities based on the inventory balance status and the likely customer demand. They show that, with this arrangement, both parties can attain maximum profit under the concept of the synergy effect. This stream of literature analyzes the impacts of the flexibility for replenishment process on firm's operation, but they do not take the customers' behavior into consideration. Even if Cachon and Swinney [28, 29] study the impact of customers' strategic behavior on quick response, they just pay attention to price adjustment or enhance system design. A more complete literature review of this line of research is provided in recent paper by Yao and Minner [30].

As an important factor affecting customers' purchase decision, reference price has received much attention from researchers. Researches on reference price effects mainly focus on pricing strategy. Krishnamurthi et al. [31] study the impact of reference price effects on brand selection and purchase quantity and show that customers have the characteristics of brand loyalty under symmetrical reference prices, while it does not appear such characteristics under the asymmetric reference price effects. Greenleaf [32] first analyzes the firm's pricing strategy with reference price effects and explains how the reference price effects affect the promotion decision of a firm during a period; it is concluded that firm's pricing decision when considering the reference price effects will increase the firm's profits. Some recent works explore how pricing strategies should account for the reference price effects, for example, see Kopalle et al. [33]; Fibich et al. [34, 35]; Popescu and Wu [36]; Nasiry and Popescu [37]; Chen et al. [38]; Hu et al. [39]; Wang (2016) and the references therein. Arslan and Kachani [40] and Mazumdar et al. [41] provide reviews of dynamic pricing model with reference price effects. However, there are few studies that consider the coordination of pricing and inventory control under reference price effects. This stream of research starts from Gimpl-Heersink [42, 43], who proves the optimality of the base-stock-list-price for single-period and two-period model when the customers are loss neutral. However, the optimality of the base-stock-list-price is stricter for the multiperiod setting. Urban [44] analyzes a single-period joint pricing and inventory model with symmetric and asymmetric reference price effects and shows that the consideration of reference price has a substantial impact on the firm's profitability. Even if the single-period profit model function is nonconcave, Zhang [45] uses a class of transformation techniques to prove the optimality of the base-stock-list-price. It is further proved that when the planning horizon is infinite, the optimal reference price trajectories converge to a steady state in both the loss neutral and loss averse cases. Taudes and Rudloff [46] provide an application of the two-period model from Gimpl-Heersink [42, 43] to electronic commodities. Güler [47] studies the joint pricing and inventory model of a single commodity under periodic review and investigates the impact of reference price on the firm's average profit via the perspective of numerical analysis. Güler et al. [14] extend the model of Gimpl-Heersink $[42,43]$ to the concave demand function, and they address the nonconcavity of the revenue function by combining the transformation technique proposed by Zhang [45] and the inverse demand function. The optimality of the state-dependent order-up-to strategy is proved for the transformed concave revenue function model. Güler et al. [15] use the safety stock as a decision variable to characterize the steady state solution to the problem when the planning horizon is infinite. Wu et al. [16] studied the optimal dynamic pricing and inventory strategy when strategic customers choose the purchase time dynamically based on historical and current prices of the commodity. Chen et al. [17] introduce a new type of concave transform technique to ensure the profit function to be concave by using the preservation property of supermodularity in parameter optimization problems with nonlattice structure proposed by Chen et al. [48] and then prove the optimality of the basestock-list-price strategy. This stream of literature captures the reference price effects on joint pricing and inventory control, but it cannot take the flexibility for replenishment process into consideration. For other related works in this stream of research, interested readers may refer to the review by Ren and Huang [49].

Although either the dynamic pricing and inventory strategy or the supply flexibility strategy is well developed by these papers, few of them delve into the discussion of joint pricing and inventory decision with supply flexibility under the reference price effects. This paper considers the joint pricing and inventory (including regular inventory and returning/expediting inventory) control problem with the 
reference price effects. Since the inventory of a commodity can influence the customer's reference price and the reference price has a significant impact on the customer's purchasing behavior. Actually, the inventory strategy and reference price interact with each other, especially within a sales period, so it is necessary to study the reference price effects' impact on both regular and returning/expediting replenishment policies. This gives reason for us to investigate the joint strategy of both the pricing and inventory with the opportunity of returns and expediting under effects of reference price.

\section{Model Description}

Consider a single-item, periodic-review inventory problem in a finite planning horizon with $T(1 \leq T \leq \infty)$ periods. The demand in period $t$ is denoted by $D_{t}$, and $\left\{D_{t} \mid t=1,2, \ldots, T\right\}$ are nonnegative random variables. Similar to Güler et al. [15] and Chen et al. [17], the demand in period $t$ is given by

$$
D_{t}\left(p_{t}, r_{t}, \epsilon_{t}\right)=\beta_{t} d_{t}\left(p_{t}, r_{t}\right)+\epsilon_{t},
$$

where $d_{t}\left(p_{t}, r_{t}\right)$ is the average demand which is a function of the sales price per unit item, denoted by $p_{t}$, and the reference price $r_{t}$ in period $t, \beta_{t}$ and $\epsilon_{t}$ are random variables of which means are 1 and 0 , respectively, and independent of $p_{t}$ and $r_{t}$. This demand function is so general that both the additive and multiplicative demand models are its special cases.

The average demand function is given by $d_{t}\left(p_{t}, r_{t}\right)=$ $\mu_{t}\left(p_{t}\right)+R_{t}\left(r_{t}-p_{t}, r_{t}\right)$, where $\mu_{t}\left(p_{t}\right)=d_{t}\left(p_{t}, p_{t}\right)$ is the base demand and $R_{t}\left(r_{t}-p_{t}, r_{t}\right)=\eta^{+} \max \left\{r_{t}-p_{t}, 0\right\}+$ $\eta^{-} \min \left\{r_{t}-p_{t}, 0\right\}$ is the reference price effects on demand [1]. The nonnegative parameters $\eta^{+}$and $\eta^{-}$measure the demand sensitivities to gain and loss of the reference cost to the sales price, respectively. Such as if $\eta^{+} \leq \eta^{-}$the demand is loss averse, if $\eta^{+}=\eta^{-}$the demand is loss neutral, and if $\eta^{+} \geq \eta^{-}$the demand is loss seeking. For more information about $R_{t}\left(r_{t}-p_{t}, r_{t}\right)$, refer to Güler $[14,15]$ and the references therein. Furthermore, the average demand function has some properties as follows.

Assumption 1. The average demand function $d_{t}\left(p_{t}, r_{t}\right)$ is concave, bounded, nonnegative, and continuous, strictly decreasing in $p_{t}$ and increasing in $r_{t}$ for $t=1,2, \ldots, T$.

It is worth mentioning that the concave hypothesis of the average demand function $d_{t}\left(p_{t}, r_{t}\right)$ is discussed in Güler et al. $[14,15]$ where customers being loss neutral or loss averse are presented in some cases. Hence, the customers in our model are loss neutral or loss averse. Moreover, with $p_{t}\left(d_{t}, r_{t}\right)$ being the inverse function of the average demand $d_{t}\left(p_{t}, r_{t}\right)$, Assumption 1 implies that $p_{t}\left(d_{t}, r_{t}\right)$ is strictly decreasing in $d_{t}$ and increasing in $r_{t}$ in every period $t$ (referring to Proposition $1,[15])$. So determining the price $p_{t}$ is equivalent to determining the average demand $d_{t}$. Accordingly in the follow-up discussion, we will focus on finding the optimal average demand $d_{t}$ in period $t$. Hence, we assume that the feasible region of the average demand $d_{t}$ in period $t$ is $\left[\underline{d}_{t}, \bar{d}_{t}\right]$ with $\underline{d}_{t} \leq \bar{d}_{t}, \underline{d}_{t} \geq 0$, and $\bar{d}_{t}<+\infty$.

Now the cost structure of the inventory system is introduced as follows. The sales price per unit item $p_{t}$ has a greatest lower bound $\underline{p}$ and a greatest upper bound $\bar{p}$ with $\underline{p} \leq p_{t} \leq \bar{p}$, which are in $\overline{d e p e n d e n t ~ o f ~ t h e i r ~ p e r i o d ~} t$. The reference price of the next period (period $t+1$ ) depends on the reference price and sales price in the current period (period $t$ ), of which modeling by the evolution of the reference price is the exponential smoothing model $[14,15,17,38,42,43]$, i.e.,

$$
r_{t+1}=\alpha r_{t}+(1-\alpha) p_{t}
$$

where $\alpha(0 \leq \alpha<1)$ is the memory parameter. This evolution shows that the reference price is generated by exponentially weighting historical prices. The larger the memory parameter $\alpha$, the longer the memory of the historical prices. If $\alpha$ is high, then customers have a long memory and past price effect is larger. If $\alpha$ is small, then current price has a greater effect than the past on the reference price. The initial reference price is given by $r_{1} \in[p, \bar{p}]$, and hence all $r_{t}$ belong to the interval. Furthermore, there is purchasing cost $c_{t}$ per unit item in period $t$ for regular order which is smaller than the greatest lower bound of the sale price $\underline{p}$, i.e., $\underline{p} \geq c_{t}$. In period $t$ we have other costs listed as follows:

$$
\begin{aligned}
& v_{t}=\text { the purchasing cost per unit item for the expedit- } \\
& \text { ing order; } \\
& s_{t}=\text { the rebate per unit return; } \\
& h_{t}=\text { the holding cost per unit item; } \\
& b_{t}=\text { the penalty cost per unit backorder. }
\end{aligned}
$$

To avoid a trivial solution, the following inequalities are satisfied $b_{t}>v_{t}>c_{t}>s_{t} \geq 0$, where $c_{t}>s_{t}$ guarantees that the firm has no incentive to make profit by ordering too much at the beginning of the period, $v_{t}>c_{t}$ indicates that the expediting order incurs a higher cost, and $b_{t}>v_{t}$ induce the firm to place the expediting order only in emergence case.

The sequence of events is as follows with all leadtimes are zero. First, at the beginning of the $t$ th period $(t=$ $1,2, \ldots, T)$, referring to the initial inventory level $x_{t}$ and current reference price $r_{t}$ the regular order $q_{t}$ is placed. The order arrives immediately. So the inventory level after regular ordering is $y_{t}=x_{t}+q_{t}$. Second, after the demand realizes by the end of the $t$ th period inventory manager either places an expediting order or returns the excess stock based on the current reference price $r_{t}$. The expediting order will be delivered with an expediting shipping mode so that it can also be used to satisfy the demand in the current period. The quantity of the expediting order or the return is denoted by $z_{t}$. If $z_{t}$ is positive, the inventory manager will return commodities back, while a negative $z_{t}$ incurs an expediting order. Further, due to the supply or return capacity constraints, the regular replenishment is limited by $Q_{t}$ and the expediting replenishment or return is not more than $M_{t}$ $\left(M_{t} \geq 0\right)$. So there may be the unsatisfied demand which is backordered after expediting replenishment. Otherwise, due to the capacity limitation of return, the firm may still have some surplus inventory. Third, all costs and revenue are incurred.

Given the initial inventory $x_{t}$ and reference price $r_{t}$ in period $t(t=1,2, \ldots, T) . V_{t}\left(x_{t}, r_{t}\right)$ represents the maximization expected profit sum from period $t$ onward and 
$J_{t}\left(y_{t}, d_{t}, r_{t}\right)$ is the expected sum of the profit from $t$ period. Then, the inventory cost control problem can be formulated as a stochastic dynamic programming and the Bellman equations for the inventory cost control can be written as follows:

$$
V_{t}\left(x_{t}, r_{t}\right)=\max _{x_{t} \leq y_{t} \leq x_{\mathrm{t}}+Q_{t}, \underline{d}_{t} \leq d_{t} \leq \bar{d}_{t}} J_{t}\left(y_{t}, d_{t}, r_{t}\right)+c_{t} x_{t},
$$

where

$$
\begin{gathered}
J_{t}\left(y_{t}, d_{t}, r_{t}\right)=\mathrm{E}\left[d_{t} \cdot p_{t}\left(d_{t}, r_{t}\right)-c_{t} y_{t}\right. \\
\left.+\max _{-M_{t} \leq z_{t} \leq\left(w_{t}\right)^{+}} H_{t}\left(z_{t}, w_{t}, r_{t+1}\right)\right],
\end{gathered}
$$

$y_{t}=x_{t}+q_{t}$ is the inventory level after placing the regular order, $w_{t}=y_{t}-D_{t}$ is the ending inventory level before returning/expediting in period $t$, and $\mathrm{E}$ denotes the averaging operator. The first term on the right-hand side of (4) is the revenue in period $t$ and $c_{t} q_{t}$ in the second term $c_{t} y_{t}=c_{t}\left(x_{t}+\right.$ $q_{t}$ ) is the purchasing cost of the regular order;

$$
\begin{aligned}
H_{t}\left(z_{t}, w_{t}, r_{t+1}\right)= & s_{t}\left(z_{t}\right)^{+}-v_{t}\left(-z_{t}\right)^{+}-h_{t}\left(w_{t}-z_{t}\right)^{+} \\
& -b_{t}\left(z_{t}-w_{t}\right)^{+} \\
& +\gamma V_{t+1}\left(w_{t}-z_{t}, r_{t+1}\right),
\end{aligned}
$$

where $(a)^{+}=\max \{a, 0\}, \gamma \in[0,1)$ is the discount factor and the first term at the right-hand side is return rebate and the second is the cost for the expediting order. The third and the fourth are the holding cost and the backorder penalty cost, respectively. The last term is the profit function for the next period.

Moreover, the terminal value of the inventory is given by $V_{T+1}\left(x_{T+1}, r_{T+1}\right)=0$, which means that there is no value left after the planning horizon ends at period $T$.

Furthermore, similar to Güler et al. [15], we make the following assumption.

Assumption 2. $p_{t}\left(d_{t}, r_{t}\right)$ which is the inverse function of the average demand $d_{t}\left(p_{t}, r_{t}\right)$ is supermodular in $\left(d_{t}, r_{t}\right)$ and the revenue function $d_{t} \cdot p_{t}\left(d_{t}, r_{t}\right)$ is joint concave in $\left(d_{t}, r_{t}\right)$.

Mention Assumption 2; according to Theorem 6 in Güler et al. [15] the revenue function $d_{t} \cdot p_{t}\left(d_{t}, r_{t}\right)$ is supermodular in $\left(d_{t}, r_{t}\right)$.

\section{Optimal Policy and Its Analysis}

In this section, the optimal decision variables are characterized including the ordering variables for regular and returning/expediting as well as pricing strategies in the inventory system. Firstly for any given $x_{t}$ and $r_{t}$ in period $t$, in order to prove the uniqueness of the optimal decision the concavities of $H_{t}$ and $J_{t}$ are important and needed.

Theorem 3. For $t=1,2, \ldots, T$, we have the following:

(i) $H_{t}\left(z_{t}, w_{t}, r_{t+1}\right)$ is joint concave in $\left(z_{t}, w_{t}, r_{t+1}\right)$ and supermodular in $\left(z_{t}, w_{t}\right)$; (ii) $J_{t}\left(y_{t}, d_{t}, r_{t}\right)$ is joint concave in $\left(y_{t}, d_{t}, r_{t}\right)$ and $V_{t}\left(x_{t}, r_{t}\right)$ is joint concave in $\left(x_{t}, r_{t}\right)$;

(iii) $V_{t}\left(x_{t}, r_{t}\right)$ is increasing in $x_{t}$ for a given $r_{t}$;

(iv) $V_{t}\left(x_{t}, r_{t}\right)$ is supermodular in $\left(x_{t}, r_{t}\right)$.

Proof. See Appendix.

Define

$$
\begin{aligned}
& \left(y_{t}^{*}\left(x_{t}, r_{t}\right), d_{t}^{*}\left(x_{t}, r_{t}\right)\right) \\
& \quad=\arg \max _{x_{t} \leq y_{t} \leq x_{t}+Q_{t}, \underline{d}_{t} \leq d_{t} \leq \bar{d}_{t}} J_{t}\left(y_{t}, d_{t}, r_{t}\right),
\end{aligned}
$$

then $y_{t}^{*}\left(x_{t}, r_{t}\right)=x_{t}+q_{t}^{*}\left(x_{t}, r_{t}\right)$ and $p_{t}^{*}\left(x_{t}, r_{t}\right)=p_{t}\left(d_{t}^{*}\left(x_{t}\right.\right.$, $\left.\left.r_{t}\right), r_{t}\right)$. Note that $y_{t}^{*}\left(x_{t}, r_{t}\right), d_{t}^{*}\left(x_{t}, r_{t}\right)$, and $q_{t}^{*}\left(x_{t}, r_{t}\right)$ are the optimal decisions in period $t$ when the initial inventory is $x_{t}$ and current reference price is $r_{t}$. Since $J_{t}\left(y_{t}, d_{t}, r_{t}\right)$ is joint concave in $\left(y_{t}, d_{t}, r_{t}\right), V_{t}\left(x_{t}, r_{t}\right)$ can be obtained through maximizing $J_{t}\left(y_{t}, d_{t}, r_{t}\right)$ sequentially, i.e.,

$$
V_{t}\left(x_{t}, r_{t}\right)=\max _{x_{t} \leq y_{t} \leq x_{t}+Q_{t}}\left[-c_{t} y_{t}+G_{t}\left(y_{t}, r_{t}\right)\right]+c_{t} x_{t}
$$

where

$$
\begin{aligned}
& G_{t}\left(y_{t}, r_{t}\right)=\max _{\underline{d}_{t} \leq d_{t} \leq \bar{d}_{t}} \mathrm{E}\left[d_{t} \cdot p_{t}\left(d_{t}, r_{t}\right)\right. \\
& \quad+\max _{-M_{t} \leq z_{t} \leq\left(y_{t}-\beta_{t} d_{t}-\epsilon_{t}\right)^{+}} H_{t}\left(z_{t}, y_{t}-\beta_{t} d_{t}-\epsilon_{t}, \alpha r_{t}\right. \\
& \left.\left.\quad+(1-\alpha) p_{t}\left(d_{t}, r_{t}\right)\right)\right]
\end{aligned}
$$

The next theorem states that $G_{t}\left(y_{t}, r_{t}\right)$ is concave in $\left(y_{t}, r_{t}\right) ; y_{t}^{*}\left(x_{t}, r_{t}\right)$ and $d_{t}^{*}\left(x_{t}, r_{t}\right)$ are increasing in initial inventory level $x_{t}$, while $q_{t}^{*}\left(x_{t}, r_{t}\right)$ and $p_{t}^{*}\left(x_{t}, r_{t}\right)$ are decreasing in $x_{t} . z_{t}^{*}\left(w_{t}, r_{t+1}\right)$ is increasing in the ending inventory level $w_{t}$ before returning/expediting in period $t$.

Theorem 4. For $t=1,2, \ldots, T$, we have the following:

(i) $G_{t}\left(y_{t}, r_{t}\right)$ is joint concave in $\left(y_{t}, r_{t}\right)$;

(ii) $y_{t}^{*}\left(x_{t}, r_{t}\right)$ is increasing in $x_{t}$ and $q_{t}^{*}\left(x_{t}, r_{t}\right)$ is decreasing in $x_{t}$;

(iii) $d_{t}^{*}\left(x_{t}, r_{t}\right)$ is increasing in $x_{t}$ and $p_{t}^{*}\left(x_{t}, r_{t}\right)$ is decreasing in $x_{t}$;

(iv) $z_{t}^{*}\left(w_{t}, r_{t+1}\right)$ is increasing in $w_{t}$, where

$$
z_{t}^{*}\left(w_{t}, r_{t+1}\right)=\arg \max _{-M_{t} \leq z_{t} \leq\left(w_{t}\right)^{+}} H_{t}\left(z_{t}, w_{t}, r_{t+1}\right) .
$$

Proof. See Appendix.

Based on Theorems 3 and 4, we can characterize the optimal inventory replenishment, pricing policies for the regular order via the theorem below, which shows that the optimal inventory replenishment policy follows a base-stock policy and the pricing policy follows a base-stock-list-price policy. Here, $\bar{y}_{t}$ and $\bar{p}_{t}$ are the base-stock level and list price in period $t$, respectively. 
Theorem 5. For $t=1,2, \ldots, T$, the optimal regular replenishment policy for $y_{t}^{*}\left(x_{t}, r_{t}\right)$ is given by

$$
y_{t}^{*}\left(x_{t}, r_{t}\right)= \begin{cases}x_{t}+Q_{t}, & \bar{y}_{t}\left(r_{t}\right)>x_{t}+Q_{t} \\ \bar{y}_{t}\left(r_{t}\right), & x_{t}<\bar{y}_{t}\left(r_{t}\right) \leq x_{t}+Q_{t} \\ x_{t}, & \bar{y}_{t}\left(r_{t}\right) \leq x_{t}\end{cases}
$$

where $\bar{y}_{t}\left(r_{t}\right)$ is given by

$$
\bar{y}_{t}\left(r_{t}\right)=\arg \max _{y_{t}}\left[-c_{t} y_{t}+G_{t}\left(y_{t}, r_{t}\right)\right]
$$

Thus, the optimal order quantity $q_{t}^{*}\left(x_{t}, r_{t}\right)$ is given by

$$
q_{t}^{*}\left(x_{t}, r_{t}\right)= \begin{cases}Q_{t}, & \bar{y}_{t}\left(r_{t}\right)>x_{t}+Q_{t}, \\ \bar{y}_{t}\left(r_{t}\right)-x_{t}, & x_{t} \leq \bar{y}_{t}\left(r_{t}\right) \leq x_{t}+Q_{t}, \\ 0, & \bar{y}_{t}\left(r_{t}\right)<x_{t}\end{cases}
$$

Furthermore, the optimal pricing policy for $p_{t}^{*}\left(x_{t}, r_{t}\right)$ is given by

$$
p_{t}^{*}\left(x_{t}, r_{t}\right)= \begin{cases}>\bar{p}_{t}\left(r_{t}\right), & \bar{y}_{t}\left(r_{t}\right)>x_{t}+Q_{t} \\ =\bar{p}_{t}\left(r_{t}\right), & x_{t} \leq \bar{y}_{t}\left(r_{t}\right) \leq x_{t}+Q_{t} \\ <\bar{p}_{t}\left(r_{t}\right), & \bar{y}_{t}\left(r_{t}\right)<x_{t}\end{cases}
$$

where $\bar{p}_{t}\left(r_{t}\right)=p_{t}\left(\bar{d}_{t}\left(r_{t}\right), r_{t}\right)$ and $\bar{d}_{t}\left(r_{t}\right)$ is given by

$$
\begin{aligned}
& \bar{d}_{t}\left(r_{t}\right)=\underset{\underline{d}_{t} \leq d_{t} \leq \bar{d}_{t}}{\arg \max _{t}}\left[d_{t} \cdot p_{t}\left(d_{t}, r_{t}\right)\right. \\
& +\max _{-M_{t} \leq z_{t} \leq\left(\bar{y}_{t}-\beta_{t} d_{t}-\epsilon_{t}\right)^{+}} H_{t}\left(z_{t}, \bar{y}_{t}-\beta_{t} d_{t}-\epsilon_{t}, \alpha r_{t}\right. \\
& \left.\left.\quad+(1-\alpha) p_{t}\left(d_{t}, r_{t}\right)\right)\right] .
\end{aligned}
$$

Proof. Firstly, we have shown that $G_{t}\left(y_{t}, r_{t}\right)$ is concave in $\left(y_{t}, r_{t}\right)$ in Theorem 4 . Because of the concavity of $G_{t}\left(y_{t}, r_{t}\right)$, it is clear that (10) holds. The optimal order quantity $q_{t}^{*}\left(x_{t}, r_{t}\right)$ follows from $q_{t}^{*}\left(x_{t}, r_{t}\right)=y_{t}^{*}\left(x_{t}, r_{t}\right)-x_{t}$.

Secondly, when $x_{t} \leq \bar{y}_{t}\left(r_{t}\right) \leq x_{t}+Q_{t}$, by (4), the optimal mean demand is given by (14). Since $p_{t}\left(d_{t}, r_{t}\right)$ is strictly decreasing in $d_{t}$, the corresponding optimal price is uniquely given by $p_{t}\left(\bar{d}_{t}, r_{t}\right)$. Together with (iii) of Theorem 4 , since $p_{t}^{*}\left(x_{t}, r_{t}\right)$ is decreasing in $x_{t}$, we thus get (13).

Let $\theta_{t}=w_{t}-z_{t}$, where $\theta_{t}$ represents the inventory level after returning/expediting. The next theorem characterizes the optimal inventory adjustment policy for returning/expediting which follows a dual-threshold policy.

Theorem 6. For $t=1,2, \ldots, T$, the optimal inventory level $\theta_{t}^{*}\left(x_{t}, r_{t}\right)$ after returning/expediting is given by the following two cases.

Case I $\left(y_{t}^{*}\left(x_{t}, r_{t}\right) \geq D_{t}\right)$. We have

$$
\theta_{t}^{*}\left(x_{t}, r_{t}\right)= \begin{cases}\min \left\{\theta_{t}^{l}, y_{t}^{*}\left(x_{t}, r_{t}\right)-D_{t}+M_{t}\right\}, & \theta_{t}^{l}>y_{t}^{*}\left(x_{t}, r_{t}\right)-D_{t}, \\ y_{t}^{*}\left(x_{t}, r_{t}\right)-D_{t}, & \theta_{t}^{l} \leq y_{t}^{*}\left(x_{t}, r_{t}\right)-D_{t} \leq \theta_{t}^{m}, \\ \left(\theta_{t}^{m}\right)^{+}, & \theta_{t}^{m}<y_{t}^{*}\left(x_{t}, r_{t}\right)-D_{t},\end{cases}
$$

where $\theta_{t}^{m}\left(x_{t}, r_{t}\right)=\arg \max _{\theta_{t}}\left\{-\left(s_{t}+h_{t}\right) \theta_{t}+\gamma V_{t+1}\left(\theta_{t}, r_{t+1}\left(x_{t}\right.\right.\right.$, $\left.\left.\left.r_{t}\right)\right)\right\}$ and $\theta_{t}^{l}\left(x_{t}, r_{t}\right)=\arg \max _{\theta_{t}}\left\{-\left(v_{t}+h_{t}\right) \theta_{t}+\gamma V_{t+1}\left(\theta_{t}\right.\right.$, $\left.\left.r_{t+1}\left(x_{t}, r_{t}\right)\right)\right\}$ with $\theta_{t}^{m}>\theta_{t}^{l}$.

Case II $\left(y_{t}^{*}\left(x_{t}, r_{t}\right)<D_{t}\right)$. We have

$$
\theta_{t}^{*}\left(x_{t}, r_{t}\right)
$$

$$
= \begin{cases}\min \left\{\theta_{t}^{l}, y_{t}^{*}\left(x_{t}, r_{t}\right)-D_{t}+M_{t}\right\}, & \theta_{t}^{l}>0, \\ \min \left\{0, y_{t}^{*}\left(x_{t}, r_{t}\right)-D_{t}+M_{t}\right\}, & \theta_{t}^{l} \leq 0 .\end{cases}
$$

Therefore, the optimal returning/expediting quantity $z_{t}^{*}\left(x_{t}, r_{t}\right)$ is given by the following two cases.

Case I $\left(y_{t}^{*}\left(x_{t}, r_{t}\right) \geq D_{t}\right)$. We have

$$
z_{t}^{*}\left(x_{t}, r_{t}\right)= \begin{cases}\max \left\{-M_{t}, y_{t}^{*}\left(x_{t}, r_{t}\right)-D_{t}-\theta_{t}^{l}\right\}, & \theta_{t}^{l}>y_{t}^{*}\left(x_{t}, r_{t}\right)-D_{t}, \\ 0, & \theta_{t}^{l} \leq y_{t}^{*}\left(x_{t}, r_{t}\right)-D_{t} \leq \theta_{t}^{m}, \\ y_{t}^{*}\left(x_{t}, r_{t}\right)-D_{t}-\left(\theta_{t}^{m}\right)^{+}, & \theta_{t}^{m}<y_{t}^{*}\left(x_{t}, r_{t}\right)-D_{t} .\end{cases}
$$


Case II $\left(y_{t}^{*}\left(x_{t}, r_{t}\right)<D_{t}\right)$. We have

$$
\begin{aligned}
z_{t}^{*} & \left(x_{t}, r_{t}\right) \\
& = \begin{cases}\max \left\{-M_{t}, y_{t}^{*}\left(x_{t}, r_{t}\right)-D_{t}-\theta_{t}^{l}\right\}, & \theta_{t}^{l}>0, \\
\max \left\{-M_{t}, y_{t}^{*}\left(x_{t}, r_{t}\right)-D_{t}\right\}, & \theta_{t}^{l} \leq 0 .\end{cases}
\end{aligned}
$$

Proof. The optimal inventory level $\theta_{t}^{*}\left(x_{t}, r_{t}\right)$ after returning/expediting given by (15) and (16) is exactly the same as the proof related to $\theta_{t}$ for Theorem 3 , while $z_{t}^{*}\left(x_{t}, r_{t}\right)$ is obtained by the definition of $\theta_{t}=w_{t}-z_{t}$.

Follows from Theorems 5 and 6, we can get the following results which demonstrate how the optimal list price $\bar{p}_{t}\left(r_{t}\right)$, the optimal mean demand $\bar{d}_{t}\left(r_{t}\right)$, the optimal base-stock level $\bar{y}_{t}\left(r_{t}\right)$, the optimal regular order quantity $q_{t}^{*}\left(x_{t}, r_{t}\right)$, and the optimal returning/expediting quantity $z_{t}^{*}\left(x_{t}, r_{t}\right)$ depend on the current reference price $r_{t}$. Moreover, we also give the change characteristics of profit-to-go function $V_{t}\left(x_{t}, r_{t}\right)$ with the current reference price $r_{t}$.

Theorem 7. For $t=1,2, \ldots, T$, we have the following:

(i) The optimal mean demand $\bar{d}_{t}\left(r_{t}\right)$ and the optimal list price $\bar{p}_{t}\left(r_{t}\right)$ are increasing in $r_{t}$.

(ii) The optimal base-stock level $\bar{y}_{t}\left(r_{t}\right)$ and the optimal regular order quantity $q_{t}^{*}\left(x_{t}, r_{t}\right)$ are increasing in $r_{t}$.

(iii) The optimal returning/expediting quantity $z_{t}^{*}\left(x_{t}, r_{t}\right)$ is decreasing in $r_{t}$.

(iv) The optimal profit-to-go function $V_{t}^{*}\left(x_{t}, r_{t}\right)$ is increasing in $r_{t}$.

Proof. (i) From the proof of (iii) in Theorem 4, we see that the function in the right-hand side of (14) is supermodularity in $\left(d_{t}, r_{t}\right)$. Thus, the monotonicity of $\bar{d}_{t}\left(r_{t}\right)$ in $r_{t}$ can be obtained which follows from Theorem 2.2.8 in Simchi-Levi et al. [50]. Since the list price $\bar{p}_{t}\left(r_{t}\right)=p_{t}\left(\bar{d}_{t}\left(r_{t}\right), r_{t}\right)$ at present is only related to $r_{t}$, therefore, $\bar{p}_{t}\left(r_{t}\right)$ is increasing in $r_{t}$ which follows from Assumption 1 in Section 2 and Proposition 1 in Güler et al. [15].

(ii) Following from the proof of (iv) in Theorem 3, we see that the function in the right-hand side in (11) is supermodular in $\left(y_{t}, r_{t}\right)$. Hence, $\bar{y}_{t}\left(r_{t}\right)$ is increasing in $r_{t}$ according to Theorem 2.2.8 in Simchi-Levi et al. [50]. In addition, according to (12), $q_{t}^{*}\left(x_{t}, r_{t}\right)$ is increasing in $r_{t}$.

(iii) Following from the supermodularity of $V_{t+1}\left(\theta_{t}, r_{t+1}\right)$ in Theorem 3 (iv) and the definition of $\theta_{t}^{l}$ and $\theta_{t}^{m},-\left(s_{t}+\right.$ $\left.h_{t}\right) \theta_{t}+\gamma V_{t+1}\left(\theta_{t}, r_{t+1}\right)$ and $-\left(v_{t}+h_{t}\right) \theta_{t}+\gamma V_{t+1}\left(\theta_{t}, r_{t+1}\right)$ are supermodular in $\left(\theta_{t}, r_{t+1}\right)$. Thus, $\theta_{t}^{l}$ and $\theta_{t}^{m}$ are increasing in $r_{t+1}$ by applying Theorem 2.2.8 in Simchi-Levi et al. [50]. Then $\theta_{t}^{*}\left(x_{t}, r_{t+1}\right)$ is increasing in $r_{t+1}$ by (15) and (16). In addition, since $r_{t+1}$ is increasing in $r_{t}$, we thus have $\theta_{t}^{*}\left(x_{t}, r_{t}\right)=$ $\theta_{t}^{*}\left(x_{t}, r_{t+1}\left(x_{t}, r_{t}\right)\right)$ increases with $r_{t}$. This, together with $\theta_{t}=$ $w_{t}-z_{t}$, yields the result.

(iv) We prove $V_{t}\left(x_{t}, r_{t}\right)$ is increasing in $r_{t}$ inductively. Let us define $\left(y_{t}^{*}\left(x_{t}, r_{t}\right), d_{t}^{*}\left(x_{t}, r_{t}\right)\right)=$ $\arg \max _{x_{t} \leq y_{t} \leq x_{t}+Q_{t}, \underline{d}_{t} \leq d_{t} \leq \bar{d}_{t}} J_{t}\left(y_{t}, d_{t}, r_{t}\right)$ for a given $r_{t}$. In order to show that $V_{T}\left(x_{T}, r_{T}\right)$ is increasing in $r_{T}$, one needs to show the following two cases.

Case $I\left(x_{T} \leq y_{T}^{*}\left(x_{T}, r_{T}\right)\right)$. The optimal solution is $\left(y_{T}^{*}\left(x_{T}, r_{T}\right), d_{T}^{*}\left(x_{T}, r_{T}\right)\right)$. Without changing the optimal pair, if $r_{t}$ is increased by an amount of $\delta>0$, the costs in (4) remain the same except for revenue term since $p_{T}\left(d_{T}, r_{T}\right)$ is increasing in $r_{T}$. Because the terminal value $V_{T+1}\left(x_{T+1}, r_{T+1}\right)=0$, the optimal solution for the new state, namely, $r_{T}+\delta$, will be larger than or equal to the current solution, that is,

$$
\begin{aligned}
V_{T}\left(x_{T}, r_{T}\right) & =J_{T}\left(y_{T}^{*}\left(x_{T}, r_{T}\right), d_{T}^{*}\left(x_{T}, r_{T}\right), r_{T}\right) \\
& \leq J_{T}\left(y_{T}^{*}\left(x_{T}, r_{T}\right), d_{T}^{*}\left(x_{T}, r_{T}\right), r_{T}+\delta\right) \\
& \leq V_{T}\left(x_{T}, r_{T}+\delta\right) .
\end{aligned}
$$

Case II. $\left(x_{T}>y_{T}^{*}\left(x_{T}, r_{T}\right)\right)$. The optimal solution is $\left(x_{T}, d_{T}^{*}\left(x_{T}, r_{T}\right)\right)$. If $r_{T}$ is increased by $\delta>0$ while the solution remains the same, the argument in Case I remains valid. Hence,

$$
\begin{aligned}
V_{T}\left(x_{T}, r_{T}\right) & =J_{T}\left(x_{T}, d_{T}^{*}\left(x_{T}, r_{T}\right), r_{T}\right) \\
& \leq J_{T}\left(x_{T}, d_{T}^{*}\left(x_{T}, r_{T}\right), r_{T}+\delta\right) \\
& \leq V_{T}\left(x_{T}, r_{T}+\delta\right) .
\end{aligned}
$$

Assume that the result holds for $t=k+1$, i.e., $V_{t+1}\left(x_{t+1}, r_{t+1}\right)$ is increasing in $r_{t+1}$. Next, we need to show that the results are still true for $t=k$.

$V_{t}\left(x_{t}, r_{t}\right)$ is increasing in $r_{t}$ which can be shown with an additional argument to the case of $V_{T}\left(x_{T}, r_{\mathrm{T}}\right)$. The terms in the profit-to-go function (3) are shown to be increasing with $r_{t}$ except for the last term $\gamma V_{t+1}\left(w_{t}-z_{t}, \alpha r_{t}+(1-\right.$ $\left.\alpha) p_{t}\left(d_{t}, r_{t}\right)\right)$. Since $p_{t}\left(d_{t}, r_{t}\right)$ increases with $r_{t}$, so $\alpha r_{t}+(1-$ $\alpha) p_{t}\left(d_{t}, r_{t}\right)$ increases with $r_{t}$. The arguments for $V_{t}\left(x_{t}, r_{t}\right)$ still remain valid since $V_{t+1}\left(x_{t+1}, r_{t+1}\right)$ is increasing in $r_{t+1}$ by the induction hypothesis. This completes the proof.

\section{The Infinite Planning Horizon Problem}

In this section, we extend above results to the infinite planning horizon case. All the cost and revenue parameters as well as demand distribution are stationary. In the analysis of infinite horizon models it is necessary to have the oneperiod reward uniformly nonpositive so that the results in negative dynamic programming can be applied. Since the original problem has no such property, we subtract a constant

$$
\Lambda=\max _{\underline{p} \leq p_{t}, r_{t} \leq \bar{p}} p_{t} \cdot d_{t}\left(p_{t}, r_{t}\right) \text {, }
$$

which is assumed to be finite from the original one period expected revenue (for $t \geq 1$ ). We then obtain the transformed profit-to-go function $\bar{V}_{t}\left(x_{t}, r_{t}\right)$ for the finite horizon problem from the original profit-to-go function $V_{t}\left(x_{t}, r_{t}\right)$ :

$$
\bar{V}_{t}\left(x_{t}, r_{t}\right)=V_{t}\left(x_{t}, r_{t}\right)-\frac{\Lambda\left(1-\gamma^{t}\right)}{1-\gamma},
$$


and

$$
\bar{J}_{t}\left(y_{t}, d_{t}, r_{t}\right)=J_{t}\left(y_{t}, d_{t}, r_{t}\right)-\frac{\Lambda\left(1-\gamma^{t}\right)}{1-\gamma} .
$$

Thus, the profit-to-go function in each period for the transformed model is nonpositive with $\bar{V}_{T+1}\left(x_{T+1}, r_{T+1}\right)=0$. So the optimal profit-to-go function of the infinite horizon problem $\bar{V}(x, r)$ satisfies the following equations (e.g., Proposition 3.1.1, [51]):

$$
\bar{V}(x, r)=\max _{x \leq y \leq x+Q, \underline{d} \leq d \leq \bar{d}} \bar{J}(y, d, r)+c x,
$$

where

$$
\begin{aligned}
& \bar{J}(y, d, r)=\mathrm{E}[d \cdot p(d, r)-c y \\
& \left.\quad+\max _{-M \leq z \leq(y-\beta d-\epsilon)^{+}} \bar{H}(z, w, \alpha r+(1-\alpha) p(d, r))\right], \\
& \bar{H}(z, w, \xi)=s(z)^{+}-v(-z)^{+}-h(w-z)^{+}-b(z \\
& \quad-w)^{+}-\Lambda+\gamma \bar{V}(w-z, \xi), \\
& w=y-\beta d-\epsilon, \\
& \xi=\alpha r+(1-\alpha) p(d, r) .
\end{aligned}
$$

In the following, we present the relationship between $\bar{V}(x, r)$ and $\bar{V}_{t}\left(x_{t}, r_{t}\right), \bar{J}(y, d, r)$ and $\bar{J}_{t}\left(y_{t}, d_{t}, r_{t}\right)$ as well as those of the original problem.

Theorem 8. (i)

$$
\begin{aligned}
\bar{V}(x, r) & =\lim _{t \rightarrow \infty} \bar{V}_{t}\left(x_{t}, r_{t}\right), \\
V(x, r) & =\lim _{t \rightarrow \infty} V_{t}\left(x_{t}, r_{t}\right), \\
\bar{J}(y, d, r) & =\lim _{t \rightarrow \infty} \bar{J}_{t}\left(y_{t}, d_{t}, r_{t}\right), \\
J(y, d, r) & =\lim _{t \rightarrow \infty} J_{t}\left(y_{t}, d_{t}, r_{t}\right) ; \text { and } \\
\bar{V}(x, r) & =V(x, r)-\frac{\Lambda}{1-\gamma}, \\
\bar{J}(y, d, r) & =J(y, d, r)-\frac{\Lambda}{1-\gamma} .
\end{aligned}
$$

(ii) $V$ and $J$ satisfy the following optimality equation:

$$
V(x, r)=\max _{x \leq y \leq x+\mathrm{Q}, \underline{d} \leq d \leq \bar{d}} J(y, d, r)+c x,
$$

where

$$
\begin{aligned}
& J(y, d, r)=\mathrm{E}[d \cdot p(d, r)-c y \\
& \left.\quad+\max _{-M \leq z \leq(y-\beta d-\epsilon)^{+}} H(z, w, \alpha r+(1-\alpha) p(d, r))\right],
\end{aligned}
$$

$$
\begin{aligned}
& H(z, w, \xi)=s(z)^{+}-v(-z)^{+}-h(w-z)^{+}-b(z \\
& -w)^{+}+\gamma V(w-z, \xi), \\
& w=y-\beta d-\epsilon, \\
& \xi=\alpha r+(1-\alpha) p(d, r) .
\end{aligned}
$$

(iii) $V(x, r)$ is concave in $(x, r)$ and is increasing in $x$ for a given $r ;(y, d, r)$ is concave in $(y, d, r)$.

Proof. (i) and (ii) follow from Theorem 3 in Section 3 and Proposition 3.1.7 in Bertsekas [51]. For (iii), $V(x, r)$ and $J(y, d, r)$ inherit the properties of $V_{t}\left(x_{t}, r_{t}\right)$ and $J_{t}\left(y_{t}, d_{t}, r_{t}\right)$.

From Propositions 3.1.3 and 3.1.7 in Bertsekas [51], there exists a stationary optimal policy for such a negative dynamic programming. The results discussed in Section 4 are presented for the infinite horizon problem via the following theorem.

Theorem 9. (i) The stationary policies for $p^{*}(x, r), q^{*}(x, r)$ and $z^{*}(x, r)\left(z^{*}(w, \xi)\right)$ are optimal.

(ii) $p^{*}(x, r)$ and $q^{*}(x, r)$ are decreasing in $x ; z^{*}(w, \xi)$ is increasing in $w$.

(iii) $V(x, r)$ is increasing in $r$, the base-stock level $\bar{y}(r)$ and the list price $\bar{p}(r)$ are increasing in $r$, and $z^{*}(x, r)$ is decreasing in $r$.

(iv) The stationary optimal policy for $q^{*}(x, r)$ is a base-stock type, the policy for $p^{*}(x, r)$ is a base-stock-listprice type, and the policy for $z^{*}(x, r)$ is a dual-threshold type.

\section{Operational Impacts of Returning/Expediting under Reference Price Effects}

To illustrate the effectiveness of our model, in this section we investigate the operational impacts from the following two aspects. On the one hand, we consider the impact of adding returning/expediting on joint pricing and inventory with reference price effects. On the other hand, we consider the impact of adding reference price effects on joint pricing and inventory with returning/expediting.

6.1. Operational Impact of Adding Returning/Expediting. We first consider the case where the firm introduces returning/expediting and study the impact on pricing and inventory control decisions with reference price effects as well as the firm's expected profit by comparing ours with that of Chen et al. [17, 38]. For simplicity of notation, we call their model CHSZ model. Although the CHSZ model considers the reference price effects, it does not take into account the returning/expediting after demand realization. To distinguish the CHSZ model from ours, we use the superscript $c$ to signify the notation for the CHSZ model. 
Since the CHSZ model is a special case of our model, i.e., $z_{t}=0$. Consequently, the corresponding optimal equation is

$$
V_{t}^{c}\left(x_{t}, r_{t}\right)=\max _{x_{t} \leq y_{t}^{c} \leq x_{t}+Q_{t}, \underline{d}_{t} \leq d_{t}^{c} \leq \bar{d}_{t}} J_{t}^{c}\left(y_{t}^{c}, d_{t}^{c}, r_{t}\right)+c_{t} x_{t} \text {, }
$$

where

$$
\begin{aligned}
& J_{t}^{c}\left(y_{t}^{c}, d_{t}^{c}, r_{t}\right)=\mathrm{E}\left[d_{t}^{c} \cdot p\left(d_{t}^{c}, r_{t}\right)-c_{t} y_{t}^{c}\right. \\
& \quad-h_{t}\left(y_{t}^{c}-\beta_{t} d_{t}^{c}-\epsilon_{t}\right)^{+}-b_{t}\left(\beta_{t} d_{t}^{c}+\epsilon_{t}-y_{t}^{c}\right)^{+} \\
& \left.\quad+\gamma V_{t+1}^{c}\left(y_{t}^{c}-\beta_{t} d_{t}^{c}-\epsilon_{t}, \alpha r_{t}+(1-\alpha) p_{t}\left(d_{t}^{c}, r_{t}\right)\right)\right] .
\end{aligned}
$$

The first result states that our model always yields an expected profit no less than the CHSZ model.

Theorem 10. After the returning/expediting is introduced, the optimal profit-to-go function satisfies $V_{t}\left(x_{t}, r_{t}\right) \geq V_{t}^{c}\left(x_{t}, r_{t}\right)$ for $t=1,2, \ldots, T$.

Proof. This follows directly from the observation that the CHSZ model is a special case of our model, i.e., $z_{t}\left(x_{t}, r_{t}\right)=0$, $t=1,2, \ldots, T$.

In what follows, we continue to discuss the operational impacts on the price, replenishment, and adjustment policy. The following theorem summarizes the relationships between the optimal policies with and without returning/expediting.

Theorem 11. After the returning/expediting is introduced, the optimal policy parameters satisfy, for $t=1,2, \ldots, T$,

(i) $z_{t}^{*} \leq 0$ iff $q_{t}^{*}\left(x_{t}, r_{t}\right) \leq q_{t}^{c *}\left(x_{t}, r_{t}\right), p_{t}^{*}\left(x_{t}, r_{t}\right) \leq$ $p_{t}^{c *}\left(x_{t}, r_{t}\right), \bar{y}_{t} \leq \bar{y}_{t}^{c}$ and $\bar{d}_{t} \geq \bar{d}_{t}^{c}$;

(ii) $z_{t}^{*}>0$ iff $q_{t}^{*}\left(x_{t}, r_{t}\right)>q_{t}^{c *}\left(x_{t}, r_{t}\right), p_{t}^{*}\left(x_{t}, r_{t}\right)>$ $p_{t}^{c *}\left(x_{t}, r_{t}\right), \bar{y}_{t}>\bar{y}_{t}^{c}$ and $\bar{d}_{t}<\bar{d}_{t}^{c}$.

Proof. We show the statement is true for $z_{t}^{*} \leq 0$. Then, the statement for $z_{t}^{*}>0$ can be shown in the similar way.

On the one hand, if $z_{t}^{*} \leq 0$, we can rewrite (8) as

$$
\begin{aligned}
& G_{t}\left(y_{t}, r_{t}\right)=\max _{\underline{d}_{t} \leq d_{t} \leq \bar{d}_{t}}\left[d_{t} \cdot p_{t}\left(d_{t}, r_{t}\right)+v_{t} z_{t}^{*} \mathrm{E} h_{t}\left(y_{t}\right.\right. \\
& \left.-\beta_{t} d_{t}-\epsilon_{t}-z_{t}^{*}\right)^{+}-\mathrm{E} b_{t}\left(\beta_{t} d_{t}+\epsilon_{t}+z_{t}^{*}-y_{t}\right)^{+} \\
& +\gamma \mathrm{E} V_{t+1}\left(y_{t}-\beta_{t} d_{t}-\epsilon_{t}-z_{t}^{*}, \alpha r_{t}\right. \\
& \left.\left.+(1-\alpha) p_{t}\left(d_{t}, r_{t}\right)\right)\right] .
\end{aligned}
$$

Then $G_{t}\left(y_{t}, r_{t}\right)$ can be seen as a function of $y_{t}, z_{t}^{*}$, and $r_{t}$. Because $G_{t}\left(y_{t}, r_{t}\right)$ is supermodular in $\left(y_{t}, z_{t}^{*}\right)$ by the concavity of $V_{t+1}$, so $\bar{y}_{t}$ is increasing in $z_{t}^{*}$ which follows from Theorem 2.2.8 in Simchi-Levi et al. [50]. Since $q_{t}^{*}\left(x_{t}, r_{t}\right)$ is increasing in $\bar{y}_{t}$ by (12) and the optimal solution of the CHSZ model can be treated as a feasible solution of our model with $z_{t}^{*}=0$, we thus have $q_{t}^{*}\left(x_{t}, r_{t}\right) \leq q_{t}^{c *}\left(x_{t}, r_{t}\right)$ and $p_{t}^{*}\left(x_{t}, r_{t}\right) \leq p_{t}^{c *}\left(x_{t}, r_{t}\right)$ for $z_{t}^{*} \leq 0$.
Next, since $J_{t}\left(y_{t}, d_{t}, r_{t}\right)$ is joint concave in $\left(y_{t}, d_{t}, r_{t}\right)$ and $z_{t}^{*}$ is given, we can rewrite (3) as

$$
\begin{aligned}
& V_{t}\left(y_{t}, r_{t}\right)=\max _{\underline{d}_{t} \leq d_{t} \leq \bar{d}_{t}}\left[d_{t} \cdot p_{t}\left(d_{t}, r_{t}\right)+v_{t} z_{t}^{*}\right. \\
& \left.+\widetilde{G}_{t}\left(\beta_{t} d_{t}+z_{t}^{*}+\epsilon_{t}, \alpha r_{t}+(1-\alpha) p_{t}\left(d_{t}, r_{t}\right)\right)\right],
\end{aligned}
$$

where

$$
\begin{aligned}
\widetilde{G}_{t} & \left(\beta_{t} d_{t}+z_{t}^{*}+\epsilon_{t}, \alpha r_{t}+(1-\alpha) p_{t}\left(d_{t}, r_{t}\right)\right) \\
& =\max _{x_{t} \leq y_{t} \leq x_{t}+Q_{t}}\left\{-c_{t} y_{t}-\mathrm{E} h_{t}\left(y_{t}-\beta_{t} d_{t}-z_{t}^{*}-\epsilon_{t}\right)^{+}\right. \\
& -\mathrm{E} b_{t}\left(\beta_{t} d_{t}+z_{t}^{*}+\epsilon_{t}-y_{t}\right)^{+}+\gamma \mathrm{E} V_{t+1}\left(y_{t}-\beta_{t} d_{t}\right. \\
& \left.\left.-z_{t}^{*}-\epsilon_{t}, \alpha r_{t}+(1-\alpha) p_{t}\left(d_{t}, r_{t}\right)\right)\right\} .
\end{aligned}
$$

To show $\bar{d}_{t}$ is decreasing in $z_{t}^{*}$, it is necessary to prove the submodularity of $\widetilde{G}_{t}\left(\beta_{t} d_{t}+z_{t}^{*}+\epsilon_{t}, \alpha r_{t}+(1-\alpha) p_{t}\left(d_{t}, r_{t}\right)\right)$ in $\left(d_{t}, z_{t}^{*}\right)$. Because the first three terms are obviously submodular, we only need the submodularity of $V_{t+1}\left(y_{t}-\beta_{t} d_{t}-\right.$ $\left.z_{t}^{*}-\epsilon_{t}, \alpha r_{t}+(1-\alpha) p_{t}\left(d_{t}, r_{t}\right)\right)$ in $\left(d_{t}, z_{t}^{*}\right)$. Fix $\epsilon_{t}$ and $r_{t}$, and consider an arbitrary pair of $\left(d_{t}^{1}, d_{t}^{2}\right)$ with $d_{t}^{1}>d_{t}^{2}$ and any pair $\left(\left(z_{t}^{*}\right)^{\prime},\left(z_{t}^{*}\right)^{\prime \prime}\right)$ with $\left(z_{t}^{*}\right)^{\prime}>\left(z_{t}^{*}\right)^{\prime \prime}$. Let $\left(\tau_{1}, r_{t+1}^{1}\right)=\left(\beta d_{t}^{1}+\right.$ $\left.\left(z_{t}^{*}\right)^{\prime}+\epsilon_{t}, r_{t+1}^{1}\right),\left(\tau_{2}, r_{t+1}^{1}\right)=\left(\beta d_{t}^{1}+\left(z_{t}^{*}\right)^{\prime \prime}+\epsilon_{t}, r_{t+1}^{1}\right),\left(\tau_{3}, r_{t+1}^{2}\right)=$ $\left(\beta d_{t}^{2}+\left(z_{t}^{*}\right)^{\prime}+\epsilon_{t}, r_{t+1}^{2}\right),\left(\tau_{4}, r_{t+1}^{2}\right)=\left(\beta d_{t}^{2}+\left(z_{t}^{*}\right)^{\prime \prime}+\epsilon_{t}, r_{t+1}^{2}\right)$, where $r_{t+1}^{1}=\alpha r_{t}+(1-\alpha) p_{t}\left(d_{t}^{1}, r_{t}\right)$ and $r_{t+1}^{2}=\alpha r_{t}+(1-\alpha) p\left(d_{t}^{2}, r_{t}\right)$. It is clear that $r_{t+1}^{1}<r_{t+1}^{2}, \tau_{1}>\tau_{3}>\tau_{4}$ and thus $y_{t}-\tau_{1}<$ $y_{t}-\tau_{3}<y_{t}-\tau_{4}$. Then we have

$$
\begin{aligned}
V_{t+1} & \left(y_{t}-\tau_{1}, r_{t+1}^{1}\right)-V_{t+1}\left(y_{t}-\tau_{3}, r_{t+1}^{2}\right) \\
\leq & V_{t+1}\left(y_{t}-\tau_{3}, r_{t+1}^{1}\right)-V_{t+1}\left(y_{t}-\tau_{3}, r_{t+1}^{2}\right) \\
\leq & V_{t+1}\left(y_{t}-\tau_{4}, r_{t+1}^{1}\right)-V_{t+1}\left(y_{t}-\tau_{4}, r_{t+1}^{2}\right) \\
\leq & V_{t+1}\left(y_{t}-\tau_{4}+\beta\left(d_{t}^{1}-d_{t}^{2}\right), r_{t+1}^{1}\right) \\
& \quad-V_{t+1}\left(y_{t}-\tau_{4}, r_{t+1}^{2}\right) \\
= & V_{t+1}\left(y_{t}-\tau_{2}, r_{t+1}^{1}\right)-V_{t+1}\left(y_{t}-\tau_{4}, r_{t+1}^{2}\right),
\end{aligned}
$$

where the first and the third inequalities follows from Theorems 5 (iii) and 1 (iii), respectively. The second inequality follows from the supermodularity of $V_{t+1}\left(x_{t+1}, r_{t+1}\right)$ by Theorem 3 (iv), and thus the difference $V_{t+1}\left(x_{t+1}, r_{t+1}^{2}\right)-$ $V_{t+1}\left(x_{t+1}, r_{t+1}^{1}\right)$ is increasing in $x_{t+1}$ for any $\xi_{2}>\xi_{1}$. Therefore, we conclude that $V_{t+1}\left(y_{t}-\beta_{t} d_{t}-z_{t}^{*}-\epsilon_{t}, \alpha r_{t}+(1-\alpha) p_{t}\left(d_{t}, r_{t}\right)\right)$ has decrease difference in $z_{t}^{*}$ for any $d_{t}^{1}>d_{t}^{2}$, which implies that $V_{t+1}\left(y_{t}-\beta_{t} d_{t}-z_{t}^{*}-\epsilon_{t}, \alpha r_{t}+(1-\alpha) p_{t}\left(d_{t}, r_{t}\right)\right)$ is submodular in $\left(d_{t}, z_{t}^{*}\right)$. Hence, $\bar{d}_{t}$ is decreasing in $z_{t}^{*}$.

By (13), since $p_{t}^{*}\left(x_{t}, r_{t}\right)$ is decreasing in $\bar{d}_{t}$, so $p_{t}^{*}\left(x_{t}, r_{t}\right)$ is increasing in $z_{t}^{*}$. Because the optimal solution of the CHSZ model can be treated as a feasible solution of our model with $z_{t}^{*}=0$, we thus have $\bar{d}_{t} \geq \bar{d}_{t}^{c}$ and $p_{t}^{*}\left(x_{t}, r_{t}\right) \leq p_{t}^{c *}\left(x_{t}, r_{t}\right)$.

On the other hand, according to the above analysis, we have shown that $\bar{y}_{t}$ is increasing in $z_{t}^{*}, q_{t}^{*}\left(x_{t}, r_{t}\right)$ is increasing 
in $z_{t}^{*}, \bar{d}_{t}$ is decreasing in $z_{t}^{*}$, and $p_{t}^{*}\left(x_{t}, r_{t}\right)$ is increasing in $z_{t}^{*}$. Therefore, if $q_{t}^{*}\left(x_{t}, r_{t}\right) \leq q_{t}^{c *}\left(x_{t}, r_{t}\right), p_{t}^{*}\left(x_{t}, r_{t}\right) \leq p_{t}^{c *}\left(x_{t}, r_{t}\right)$, $\bar{y}_{t} \leq \bar{y}_{t}^{c}$, and $\bar{d}_{t} \geq \bar{d}_{t}^{c}$, we have $z_{t}^{*} \leq 0$ since the optimal solution of the CHSZ model can be treated as a feasible solution of our model with $z_{t}^{*}=0$. This completes the proof.

We offer the following interpretation of Theorem 11. Part (i) of this theorem is obvious: when the firm has the opportunity of expediting, the firm has the new option when needed to raise the inventory level; hence, it can reduce the base-stock level from the regular order, so the order quantity will also decrease. The optimal list price in our system is lower than that of CHSZ model. As a result, the mean demand will increase. Part (ii) is exactly the opposite situation.

6.2. Operational Impact of Adding Reference Price Effects. We next analyze the operational impact of reference price effects on joint pricing and inventory with returning/expediting by comparing ours with that of Zhu [9]. For simplicity of notation, we call their model ZS model. Although the ZS model considers returning/expedition after the demand is realized, it does not take the reference price effects into consideration. To distinguish the ZS model from ours, we use the superscript $f$ to signify the notation for the ZS model. The following is the main results on the impact of adding the reference price effects.

Theorem 12. After the reference price effects is considered, the optimal profit-to-go function and optimal policy parameters satisfy, fort $=1,2, \ldots, T$,

(i) $V_{t}\left(x_{t}, r_{t}\right) \geq V_{t}^{f}\left(x_{t}\right)$;

(ii) $\bar{y}_{t} \geq \bar{y}_{t}^{f}$;

(iii) $q_{t}^{*}\left(x_{t}, r_{t}\right) \geq q_{t}^{f *}\left(x_{t}\right)$;

(iv) $\bar{p}_{t} \geq \bar{p}_{t}^{f}$;

(v) $\bar{d}_{t} \geq \bar{d}_{t}^{f}$;

(vi) $z_{t}^{*}\left(x_{t}, r_{t}\right) \leq z_{t}^{f *}\left(x_{t}\right)$.

Proof. Since the ZS model is a special case of our model, i.e., $r_{t}=0, t=1,2, \ldots, T$. This, together with Theorem 7 implies these results.

This theorem can be intuitively illustrated as follows. When the firm does not consider the customers' reference price, the ordering strategy would be relatively conservative. However, when the firm takes the customers' reference price into consideration, with the increase of customers' reference price, the mean demand will increase, the order quantity will also increase and so is the inventory level, and the firm's price will rise, so the profit increases. Furthermore, for part (vi), when $z_{t} \leq 0$, the expediting quantity will increase compared with that without considering the reference price effects due to the high demand. When $z_{t}>0$, the returning quantity will decrease compared with that without considering the reference price effects. This is because the ordering decision which consider the reference price effects are more precise than that of without considering the reference price effects.

\section{Numerical Analysis}

In this section, we proceed several numerical experiments used to illustrate the following two aspects. Firstly, verify the accuracy of the conclusions of this paper. Secondly, analyze the operational impacts on firm's profit by adding returning/expediting and reference price effects via comparing ours with those of CHSZ and ZS model.

We consider a system with planning horizon $T=4$. Suppose the following stationary parameter values: $c_{t}=10$, $s_{t}=9, v_{t}=12, h_{t}=1.5, b_{t}=15, \eta^{+}=1.5, \eta^{-}=$ $2.5, \gamma=0.95, \alpha=0.5, Q_{t}=200$, and $M_{t}=50$. The mean demand function is assumed to be additive, i.e., $d_{t}\left(p_{t}, r_{t}\right)=200-15 p_{t}+1.5 \max \left\{r_{t}-p_{t}, 0\right\}+2.5 \min \left\{r_{t}-p_{t}, 0\right\}$. Moreover, we assume that $\beta_{t} \sim$ Uniform $[0.5,1.5]$ and $\epsilon_{t} \sim$ Uniform $[-0.5,0.5]$. All experiments below are performed in MATLAB R2014b on a laptop with an Intel(R) Core (TM) i5-7200U central processing unit CPU $(2.50 \mathrm{GHz}, 2.70 \mathrm{GHz})$ and $8.0 \mathrm{~GB}$ of RAM running 64-bit Windows 10 Enterprise.

Figures 1(a)-1(c) give the trends of optimal regular basestock level $y_{t}^{*}$, optimal regular order quantity $q_{t}^{*}$, and optimal price $p_{t}^{*}$ with initial inventory $x_{t}$ and reference price $r_{t}$, respectively, which are consistent with Theorems 4 and 7 . This indicates that, with the increase of customers' reference price, customers valuation of commodities will increase; the firm will increase the price and raise its inventory level (order quantity) for regular supply to gain more profit. Therefore, reference price has a positive effect on optimal price, optimal inventory level, and optimal order quantity. Figure 1(d) illustrates the impact of current reference price $r_{t}$ on optimal expediting or returning quantity $z_{t}^{*}$, which is also consistent with Theorem 7 . Figure $1(\mathrm{~d})$ indicates that when the customers' reference price is high, the customers' valuation of the commodities will increase, so the firm will increase the expediting replenishment order quantity (or reduce the quantity of returning) to meet the increasing demand. In addition, it is shown from Figure 1(d) that the optimal returning or expediting quantity $z_{t}^{*}$ decreases with memory parameter $\alpha$; this suggests that the firm should decrease the expediting replenishment order quantity (or increase the quantity of returning) to save the holding cost when consumers have short-term memories of previous commodities' prices or are less loyal to its commodities.

Figure 2 provides the comparison of optimal profit among ours, CHSZ, and ZS model. We set $\beta_{t} \sim$ Uniform $[0.5,1.5]$, and let $\epsilon_{t}$ follow the uniform distribution on $[-0.5,0.5]$, normal distribution with mean 0 , and standard deviation 25 , respectively. Figure 2 shows that when $\epsilon_{t}$ takes these two different distributions, even if the firm can either benefit from returning/expediting or benefit from reference price effects. However, considering both returning/expediting and reference price effects will bring more profit than just considering one of the two aspects. 


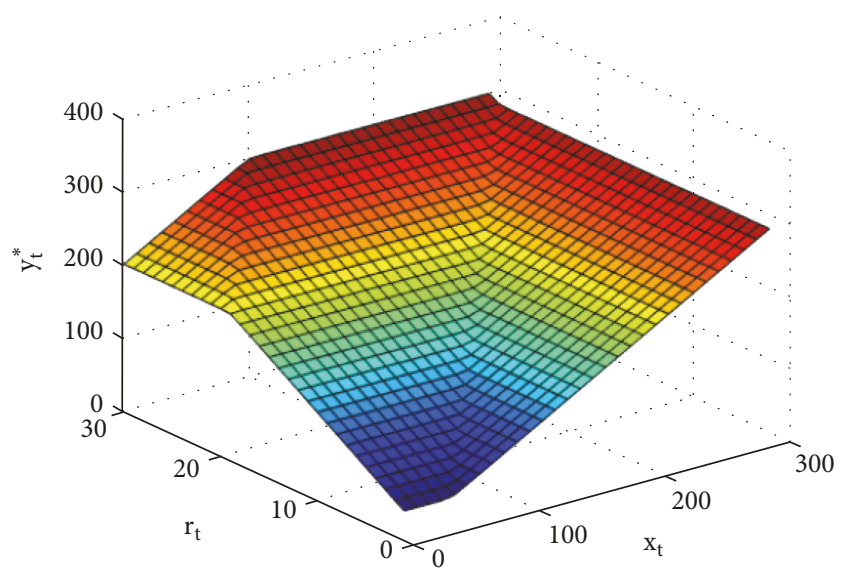

(a) The optimal base-stock level $y_{t}^{*}$ via $x_{t}$ and $r_{t}$

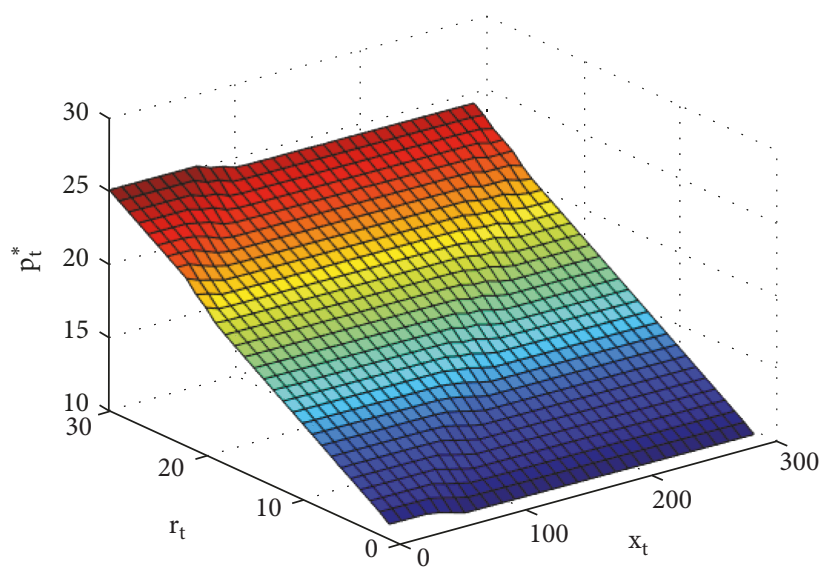

(c) The optimal price $p_{t}^{*}$ via $x_{t}$ and $r_{t}$

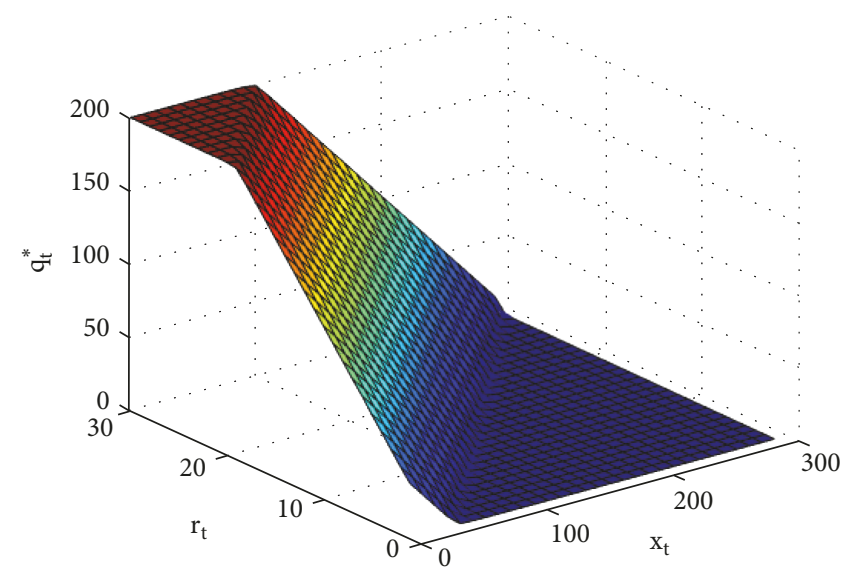

(b) The optimal order quantity $q_{t}^{*}$ via $x_{t}$ and $r_{t}$

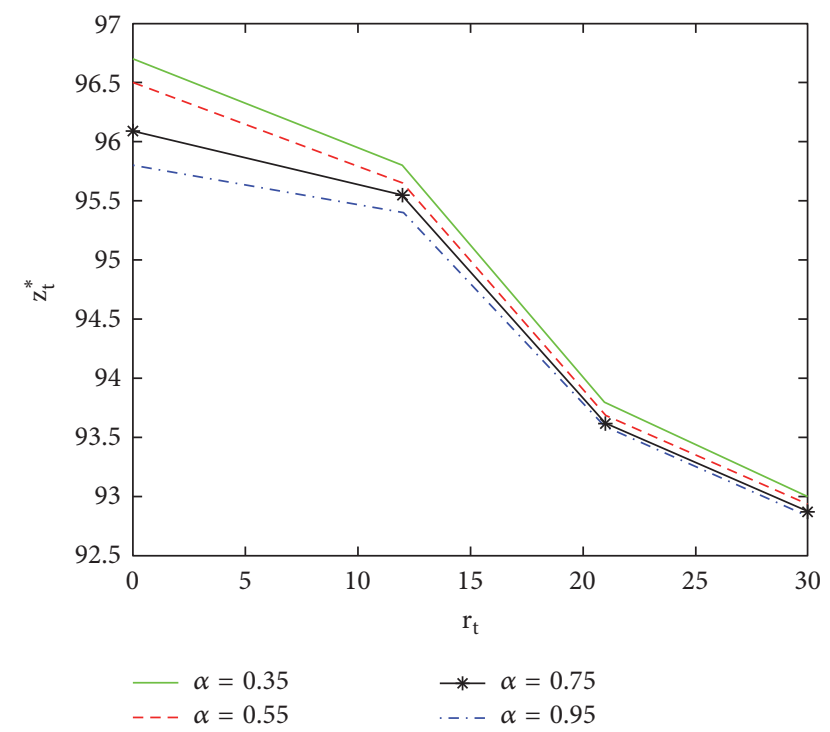

(d) The optimal expediting/returning quantity $z_{t}^{*}$ via $r_{t}$

FIgURE 1: The optimal regular and expediting/returning decisions under reference price effects.

\section{Conclusion}

Our research complements the existing research stream in coordinating pricing and inventory replenishment decisions from two aspects. On the one hand, we consider the inventory planning decisions for returns and expediting. On the other hand, we consider the influence of the customers' behavior (i.e., customers' reference price) on the joint pricing and inventory replenishment decisions.

In this paper, we investigate a single-item periodic-review finite horizon joint pricing and inventory replenishment problem with returns and expediting under reference price effects. Demand in each period is random and sensitive to price and reference price. At the beginning of each period, the firm first observes the current inventory level and simultaneously decides the unit selling price and the quantity of the regular order for the current period based on the current reference price. At the end of each period, after the demand is realized, a firm can return excess stocks to a supplier. Or, if there are stockouts, the firm can place an expediting order at the supplier to reduce the amount of shortage. Unfilled demands are fully backlogged. For a very general stochastic demand function, our research shows that the optimal replenishment policy for regular order is a basestock policy, the optimal pricing policy is a base-stock-listprice policy, and the optimal policy for returning/expediting inventory adjustment follows a dual-threshold policy. We further analyze the operational effects of returns and expediting under reference price effects by comparing ours with that of Chen et al. [17] and Zhu [9], respectively. Numerical results also demonstrate that considering both returning/expediting and reference price effects will bring more benefits than considering only one of them.

Though this paper has identified the effects of reference price on dynamic pricing and ordering for regular and returning/expediting decisions, there are still some shortcomings that can be investigated in the future. First, this paper analyzes the pricing and order decisions of a single firm 


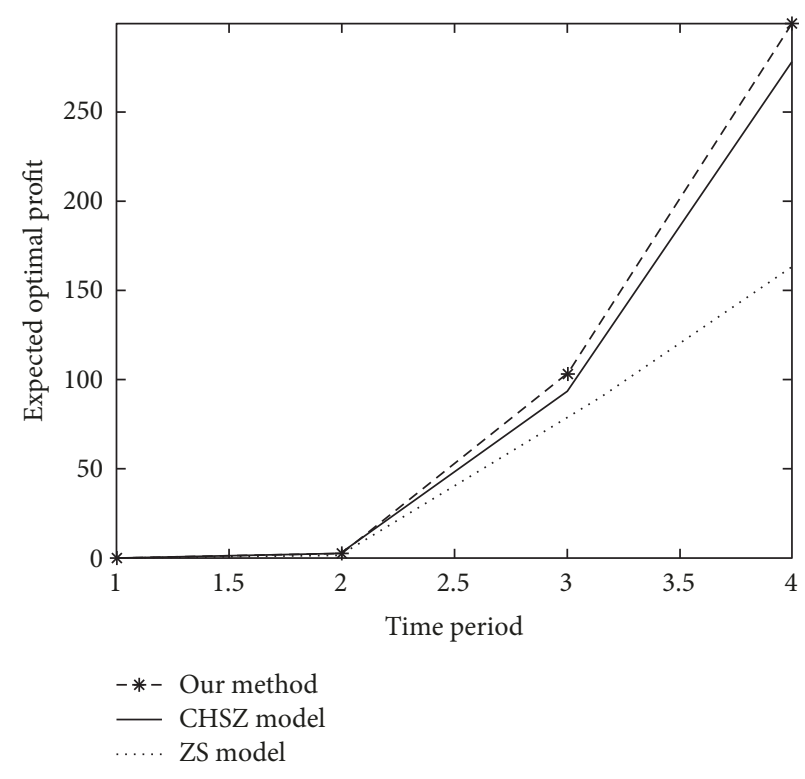

(a) $\beta_{t} \sim$ Uniform $[0.5,1.5], \epsilon_{t} \sim$ Uniform $[-0.5,0.5]$

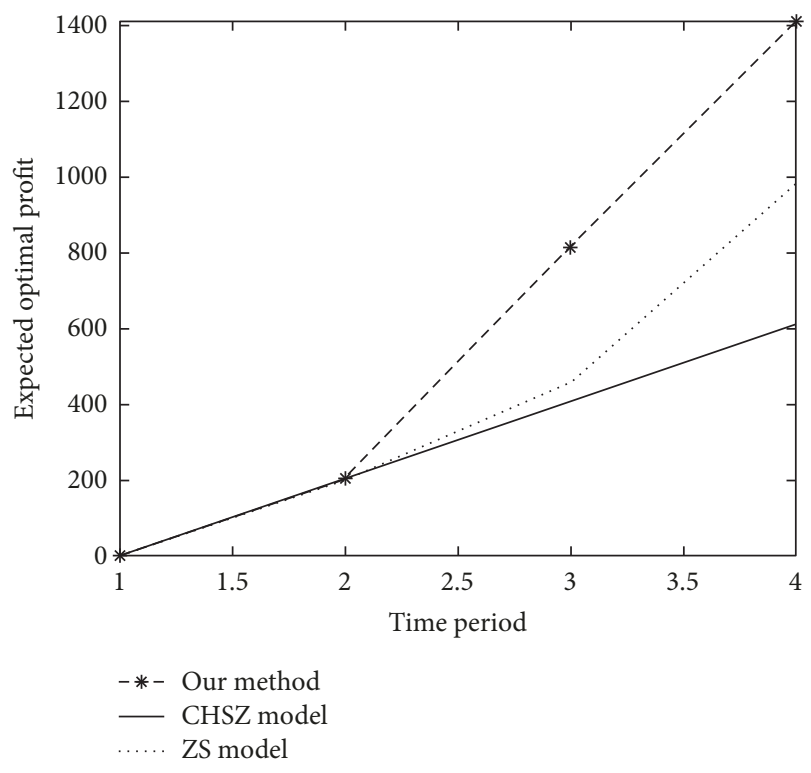

(b) $\beta_{t} \sim$ Uniform $[0.5,1.5], \epsilon_{t} \sim N\left(0,25^{2}\right)$

Figure 2: The comparison of optimal profit among ours, CHSZ, and ZS model.

under reference price effects and unaware of the influence of reference price effects on suppliers. An interesting future research topic is to examine the pricing and inventory decisions for suppliers, and to design an appropriate coordination mechanism so that a win-win outcome for both parties can be obtained. Second, in our study, the customers reference price can be observed by firms. However, the information on customers reference price is difficult to get in reality. Thus, demand learning can be incorporated into formulating pricing and inventory strategy in the presence of the reference price effects. Third, with the rapid development of information technology centered on the mobile Internet, customers purchase patterns are also diversified. In this case, how to study the reference price of customers on firms pricing and inventory decisions is also one of interesting and meaningful research directions in the future.

\section{Appendix}

Proof of Theorem 3. (i), (ii), and (iii) of this theorem will be proved together by induction. Starting from $t=T$, it is obvious that $H_{T}\left(z_{T}, w_{T}, r_{T+1}\right)$ is joint concave in $\left(z_{T}, w_{T}, r_{T+1}\right)$. Thus, $J_{T}\left(y_{T}, d_{T}, r_{T}\right)$ is joint concave in $\left(y_{T}, d_{T}, r_{T}\right)$. Similar to the proof of Lemma 1 in Zhu [9], we have that

$$
\begin{aligned}
& \max _{-M_{T} \leq z_{T} \leq\left(w_{T}\right)^{+}} H_{T}\left(z_{T}, w_{T}, r_{T+1}\right) \\
& =\max _{-M_{T} \leq z_{T}} H_{T}\left(z_{T}, w_{T}, r_{T+1}\right) .
\end{aligned}
$$

Because (A.1) is true, we can optimize $z_{T}$ based on the set $\left\{z_{T} \mid-M_{T} \leq z_{T}\right\}$. Since $H_{T}\left(z_{T}, w_{T}, r_{T+1}\right)$ is joint concave on convex set $\left\{z \mid-M_{T} \leq z_{T}\right\}$ and concavity is preserved by maximization, combination with Assumption 2 yields the concavity of $J_{T}\left(y_{T}, d_{T}, r_{T}\right)$ in $\left(y_{T}, d_{T}, r_{T}\right)$. Then $V_{T}\left(x_{T}, r_{T}\right)$ is concave in $\left(x_{T}, r_{T}\right)$ since maximization preserves concavity.
Next, we will show that $V_{T}\left(x_{T}, r_{T}\right)$ is increasing in $x_{T}$ by proving $\partial V_{T}\left(x_{T}, r_{T}\right) / \partial x_{T} \geq 0$ for a given $r_{T}$. Since $J_{T}\left(y_{T}, d_{T}, r_{T}\right)$ is joint concave in $\left(y_{T}, d_{T}, r_{T}\right)$, we can rewrite $V_{T}\left(x_{T}, r_{T}\right)$ as

$$
\begin{aligned}
V_{T}\left(x_{T}, r_{T}\right)= & \max _{x_{T} \leq y_{T} \leq x_{T}+Q_{T}}\left[-c_{T} y_{T}+G_{T}\left(y_{T}, r_{T}\right)\right] \\
& +c_{T} x_{T},
\end{aligned}
$$

where

$$
\begin{aligned}
& G_{T}\left(y_{T}, r_{T}\right)=\max _{\underline{d}_{T} \leq d_{T} \leq \bar{d}_{T}} \mathrm{E}\left[d_{T} \cdot p_{T}\left(d_{T}, r_{T}\right)\right. \\
& \quad+\max _{-M_{T} \leq z_{T}} H_{T}\left(z_{T}, y_{T}-\beta_{T} d_{T}-\epsilon_{T}, \alpha r_{T}\right. \\
& \left.\left.\quad+(1-\alpha) p_{T}\left(d_{T}, r_{T}\right)\right)\right],
\end{aligned}
$$

Denote $\bar{y}_{T}=\arg \max _{y_{T}}\left[-c_{T} y_{T}+G_{T}\left(y_{T}, r_{T}\right)\right]$. Following from the concavity of $V_{T}$, it is clear that $\partial V_{T}\left(x_{T}, r_{T}\right) / \partial x_{T} \geq c_{T}$ for $x_{T} \leq \bar{y}_{T}$. For $x_{T}>\bar{y}_{T}$, we have $\partial V_{T}\left(x_{T}, r_{T}\right) / \partial x_{T}=$ $\partial G_{T}\left(x_{T}, r_{T}\right) / \partial x_{T} \geq \partial G_{T}\left(x_{T}, r_{T}\right) /\left.\partial x_{T}\right|_{x_{T} \rightarrow+\infty}$. Besides, we have

$$
\begin{aligned}
& \left.\frac{\partial G_{T}\left(x_{T}, r_{T}\right)}{\partial x_{T}}\right|_{x_{T} \rightarrow+\infty}=\lim _{x_{T} \rightarrow+\infty}\left\{s_{T} \Phi_{T}\left(x_{T}\right)\right. \\
& +v_{T}\left[\Phi_{T}\left(x_{T}+M_{T}\right)-\Phi_{T}\left(x_{T}\right)\right] \\
& \left.+b_{T}\left[1-\Phi_{T}\left(x_{T}+M_{T}\right)\right]\right\}=s_{T} \geq 0 .
\end{aligned}
$$

where $\Phi_{T}$ is the cumulative distribution function of $D_{T}$. Thus, we obtain $\partial V_{T}\left(x_{T}, r_{T}\right) / \partial x_{T} \geq 0$ for a given $r_{T}$.

Assume that the results hold for $t=k+1$. Next, we need to show that the results are still true for $t=k$. 
By induction, since $V_{k+1}\left(x_{k+1}, r_{k+1}\right)$ is concave in $\left(x_{k+1}\right.$, $\left.r_{k+1}\right), H_{k}\left(z_{k}, w_{k}, r_{k+1}\right)$ is joint concave in $\left(z_{k}, w_{k}, r_{k+1}\right)$. By definition, we have

$$
\begin{aligned}
H_{k}\left(z_{k}, w_{k}, r_{k+1}\right)= & s_{k}\left(z_{k}\right)^{+}-v_{k}\left(-z_{k}\right)^{+} \\
& -h_{k}\left(w_{k}-z_{k}\right)^{+}-b_{k}\left(z_{k}-w_{k}\right)^{+} \\
& +\gamma V_{k+1}\left(w_{k}-z_{k}, r_{k+1}\right)
\end{aligned}
$$

Now, we intend to show that

$$
\begin{array}{r}
\max _{-M_{k} \leq z_{k} \leq\left(w_{k}\right)^{+}} H_{k}\left(z_{k}, w_{k}, r_{k+1}\right) \\
=\max _{-M_{k} \leq z_{k}} H_{k}\left(z_{k}, w_{k}, r_{k+1}\right),
\end{array}
$$

and we consider the following two cases: $w_{k} \geq 0$ and $w_{k}<0$.

Case $I\left(w_{k} \geq 0\right)$. By (4), we have $-M_{k} \leq z_{k} \leq w_{k}$. For $z_{k}>w_{k}$, we have

$$
\begin{aligned}
& H_{k}\left(z_{k}, w_{k}, r_{k+1}\right) \\
& \quad=b_{k} w_{k} \\
& \quad+\max _{z_{k} \geq w_{k}}\left[-\left(b_{k}-s_{k}\right) z_{k}+\gamma V_{k+1}\left(w_{k}-z_{k}, r_{k+1}\right)\right] .
\end{aligned}
$$

Since $b_{k}>s_{k}$ and $V_{k+1}\left(x_{k+1}, r_{k+1}\right) / \partial x_{k+1} \geq 0$ for a fixed $r_{k+1}$, it is clear that $H_{k}\left(z_{k}, w_{k}, r_{k+1}\right)$ is decrease in $z_{k}$ for $z_{k}>$ $w_{k}$. Then, we get $H_{k}\left(z_{k}, w_{k}, r_{k+1}\right) \leq H_{k}\left(w_{k}, w_{k}, r_{k+1}\right)$ for $z_{k}>$ $w_{k}$. Thus, (A.6) is true.

Case II $\left(w_{k}<0\right)$. By (4), we have $-M_{k} \leq z_{k} \leq 0$. For $z_{k}>0$, we have

$$
\begin{aligned}
& H_{k}\left(z_{k}, w_{k}, r_{k+1}\right) \\
& =b_{k} w_{k} \\
& \quad+\max _{z_{k} \geq 0}\left[-\left(b_{k}-s_{k}\right) z_{k}+\gamma V_{k+1}\left(w_{k}-z_{k}, r_{k+1}\right)\right] .
\end{aligned}
$$

By following the similar argument like that of Case I, it is clear that $H_{k}\left(z_{k}, w_{k}, r_{k+1}\right) \leq H_{k}\left(0, w_{k}, r_{k+1}\right)$ for $z_{k}>0$. Thus, (A.6) is still true.

Because (A.6) is true, we can optimize $z_{k}$ based on the set $\left\{z_{k} \mid-M_{k} \leq z_{k}\right\}$. Since $H_{k}\left(z_{k}, w_{k}, r_{k+1}\right)$ is joint concave on the convex set $\left\{z_{k} \mid-M_{k} \leq z_{k}\right\}$ and concavity is preserved by maximization, then $J_{k}\left(y_{k}, d_{k}, r_{k}\right)$ is joint concave in $\left(y_{k}, d_{k}, r_{k}\right)$. Therefore, we obtain that $V_{k}\left(x_{k}, r_{k}\right)$ is concave in $\left(x_{k}, r_{k}\right)$.

Next, we will show that $\partial V_{k}\left(x_{k}, r_{k}\right) / \partial x_{k} \geq 0$ for a given $r_{k}$. Since $J_{k}\left(y_{k}, d_{k}, r_{k}\right)$ is joint concave in $\left(y_{k}, d_{k}, r_{k}\right)$, we can rewrite $V_{k}\left(x_{k}, r_{k}\right)$ as

$$
\begin{aligned}
V_{k}\left(x_{k}, r_{k}\right)= & \max _{x_{k} \leq y_{k} \leq x_{k}+Q_{k}}\left[-c_{k} y_{k}+G_{k}\left(y_{k}, r_{k}\right)\right] \\
& +c_{k} x_{k}
\end{aligned}
$$

where

$$
\begin{aligned}
& G_{k}\left(y_{k}, r_{k}\right)=\max _{\underline{d}_{k} \leq d_{k} \leq \bar{d}_{k}} \mathrm{E}\left[d_{k} \cdot p_{k}\left(d_{k}, r_{k}\right)\right. \\
& \quad+\max _{-M_{k} \leq z_{k} \leq\left(y_{k}-\beta_{k} d_{k}-\epsilon_{k}\right)^{+}} H_{k}\left(z_{k}, y_{k}-\beta_{k} d_{k}-\epsilon_{k}, \alpha r_{k}\right. \\
& \left.\left.\quad+(1-\alpha) p_{k}\left(d_{k}, r_{k}\right)\right)\right]
\end{aligned}
$$

Denote $\bar{y}_{k}=\arg \max _{y_{k}}\left[-c_{k} y_{k}+G_{k}\left(y_{k}, r_{k}\right)\right]$. Because of the concavity of $V_{k}$, it is clear that $\partial V_{k}\left(x_{k}, r_{k}\right) / \partial x_{k} \geq c_{k}$ for $x_{k} \leq$ $\bar{y}_{k}$. For $x_{k}>\bar{y}_{k}$, we have $\partial V_{k}\left(x_{k}, r_{k}\right) / \partial x_{k}=\partial G_{k}\left(x_{k}, r_{k}\right) / \partial x_{k} \geq$ $\partial G_{k}\left(x_{k}, r_{k}\right) /\left.\partial x_{k}\right|_{x_{k} \longrightarrow+\infty}$.

Now, we need to show that $G_{k}\left(x_{k}, r_{k}\right) /\left.\partial x_{k}\right|_{x_{k} \longrightarrow+\infty} \geq 0$. Because $G_{k}\left(x_{k}, r_{k}\right)$ depends on the maximum of $H_{k}\left(z_{k}, w_{k}, r_{k+1}\right)$, we need to firstly analyze the maximum of $H_{k}\left(z_{k}, w_{k}, r_{k+1}\right)$. Then, conditioning on the value of $w_{k}$, we consider two cases: $w_{k} \geq 0$ and $w_{k}<0$. To brief notation, we denote $\theta_{k}=w_{k}-z_{k}$. To optimize $z_{k}$ which is equivalent to optimize $\theta_{k}$, we rewrite

$$
\begin{aligned}
H_{k}\left(\theta_{k}, w_{k}, r_{k+1}\right)= & s_{k}\left(w_{k}-\theta_{k}\right)^{+}-v_{k}\left(\theta_{k}-w_{k}\right)^{+} \\
& -h_{k}\left(\theta_{k}\right)^{+}-b_{k}\left(-\theta_{k}\right)^{+} \\
& +\gamma V_{k+1}\left(\theta_{k}, r_{k+1}\right) .
\end{aligned}
$$

Define

$$
\begin{aligned}
& \theta_{k}^{l}\left(x_{k}, r_{k}\right)=\theta_{k}^{l}\left(r_{k+1}\right) \\
& =\arg \max _{\theta_{k}}\left\{-\left(v_{k}+h_{k}\right) \theta_{k}+\gamma V_{k+1}\left(\theta_{k}, r_{k+1}\right)\right\}, \\
& \theta_{k}^{m}\left(x_{k}, r_{k}\right)=\theta_{k}^{m}\left(r_{k+1}\right) \\
& \quad=\arg \max _{\theta_{k}}\left\{-\left(s_{k}+h_{k}\right) \theta_{k}+\gamma V_{k+1}\left(\theta_{k}, r_{k+1}\right)\right\} .
\end{aligned}
$$

$\theta_{k}^{l}\left(r_{k+1}\right) \leq \theta_{k}^{m}\left(r_{k+1}\right)$ because of the concavity of $V_{k+1}$ and $v_{k}>$ $s_{k}$.

Case $I\left(w_{k} \geq 0\right)$. By (4), since $-M_{k} \leq z_{k} \leq w_{k}$, we have $0 \leq \theta_{k} \leq w_{k}+M_{k}$. Substituting $\theta_{k}$ into (5), we define

$$
\begin{aligned}
Y_{k}^{(1)}= & s_{k} \mathrm{w}_{k} \\
& +\max _{\theta_{k} \leq w_{k}}\left\{-\left(s_{k}+h_{k}\right) \theta_{k}+\gamma V_{k+1}\left(\theta_{k}, r_{k+1}\right)\right\},
\end{aligned}
$$

and

$$
\begin{aligned}
W_{k}^{(1)}= & v_{k} w_{k} \\
& +\max _{\theta_{k} \geq w_{k}}\left\{-\left(v_{k}+h_{k}\right) \theta_{k}+\gamma V_{k+1}\left(\theta_{k}, r_{k+1}\right)\right\} .
\end{aligned}
$$

According to the above analysis, $\theta_{k}^{*}\left(r_{k+1}\right)$ depends on the relationship between two thresholds $\left(\theta_{k}^{l}\left(r_{k+1}\right)\right.$ and $\left.\theta_{k}^{m}\left(r_{k+1}\right)\right)$ and $w_{k}$. In other words, we need to consider three different subcases. 
Case I- $a\left(w_{k}<\theta_{k}^{l}\left(r_{k+1}\right)\right)$. We have

$$
\begin{aligned}
W_{k}^{(1)}= & v_{k} w_{k}-\left(v_{k}+h_{k}\right) \theta_{k}^{l}\left(r_{k+1}\right) \\
& +\gamma V_{k+1}\left(\theta_{k}^{l}\left(r_{k+1}\right), r_{k+1}\right) \\
\geq & -h_{k} w_{k}+\gamma V_{k+1}\left(w_{k}, r_{k+1}\right)=Y_{k}^{(1)},
\end{aligned}
$$

where the inequality is true since $\theta_{k}^{l}\left(r_{k+1}\right)$ yields the maximal $W_{k}^{(1)}$. So, it is profitable to increase the inventory level from $w_{k}$ to $\theta_{k}^{l}\left(r_{k+1}\right)$. However, since the amount of the expediting order is limited by $M_{k}$, we have $\theta_{k}^{*}\left(r_{k+1}\right)=\min \left\{\theta_{k}^{l}\left(r_{k+1}\right), \mathrm{w}_{k}+\right.$ $\left.M_{k}\right\}$. Note that $H_{k}\left(w_{k}+M_{k}, w_{k}, r_{k+1}\right) \geq H_{k}\left(w_{k}, w_{k}, r_{k+1}\right)$ if $\theta_{k}^{l}\left(r_{k+1}\right) \geq w_{k}+M_{k}$.

Case I- $b\left(\theta_{k}^{l}\left(r_{k+1}\right) \leq w_{k} \leq \theta_{k}^{m}\left(r_{k+1}\right)\right)$. It is straightforward to verify that $W_{k}^{(1)}=-h_{k} w_{k}+\gamma V_{k+1}\left(w_{k}, r_{k+1}\right)=Y_{k}^{(1)}$. Consequently, the firm has no incentive to make adjustment, i.e., $\theta_{k}^{*}\left(r_{k+1}\right)=w_{k}$.

Case I-c $\left(\theta_{k}^{m}\left(r_{k+1}\right)<w_{k}\right)$. We have

$$
\begin{aligned}
W_{k}^{(1)}= & -h_{k} w_{k}+\gamma V_{k+1}\left(w_{k}, r_{k+1}\right) \\
\leq & s_{k} w_{k}-\left(s_{k}+h_{k}\right) \theta_{k}^{m}\left(r_{k+1}\right) \\
& +\gamma V_{k+1}\left(\theta_{k}^{m}\left(r_{k+1}\right), r_{k+1}\right)=Y_{k}^{(1)},
\end{aligned}
$$

where the inequality is true since $\theta_{k}^{m}\left(r_{k+1}\right)$ yields the maximal $Y_{k}^{(1)}$. So, it is profitable to reduce the inventory level to $\theta_{k}^{m}\left(r_{k+1}\right)$. However, since $\theta_{k} \geq 0$, we have $\theta_{k}^{*}\left(r_{k+1}\right)=$ $\left(\theta_{k}^{m}\left(r_{k+1}\right)\right)^{+}$, which means that the firm cannot return more stock than he or she has.

Case II $\left(w_{k}<0\right)$. By $(4)$, since $-M_{k} \leq z_{k} \leq 0$, we have $w_{k} \leq$ $\theta_{k} \leq w_{k}+M_{k}$. Substituting $\theta_{k}$ into (5), we have

$$
\begin{aligned}
Y_{k}^{(2)}= & v_{k} w_{k} \\
& +\max _{\theta_{k} \leq 0}\left[\left(b_{k}-v_{k}\right) \theta_{k}+\gamma V_{k+1}\left(\theta_{k}, r_{k+1}\right)\right],
\end{aligned}
$$

and

$$
\begin{aligned}
W_{k}^{(2)}= & v_{k} w_{k} \\
& +\max _{\theta_{k} \geq 0}\left[-\left(v_{k}+b_{k}\right) \theta_{k}+\gamma V_{k+1}\left(\theta_{k}, r_{k+1}\right)\right] .
\end{aligned}
$$

Since $b_{k}>v_{k}$ and $\partial V_{k+1}\left(x_{k+1}, r_{k+1}\right) / \partial x_{k+1} \geq s_{k+1}$ for given $r_{k+1}$, we have $Y_{k}^{(2)}=H_{k}\left(0, w_{k}, r_{k+1}\right)=v_{t} w_{k}+\gamma V_{k+1}\left(0, r_{k+1}\right)$. According to the above analysis, $\theta_{k}^{*}\left(r_{k+1}\right)$ depends on the relationship between $\theta_{k}^{l}\left(r_{k+1}\right)$ and $w_{k}$. In other words, we need to consider two different subcases.

Case II-a $\left(\theta_{k}^{l}\left(r_{k+1}\right)>0\right)$. We have

$$
\begin{aligned}
W_{k}^{(2)}= & v_{k} w_{k}-\left(v_{k}+h_{k}\right) \theta_{k}^{l}\left(r_{k+1}\right) \\
& +\gamma V_{k+1}\left(\theta_{k}^{l}\left(r_{k+1}\right), r_{k+1}\right) \\
\geq & v_{k} w+\gamma V_{k+1}\left(0, r_{k+1}\right)=Y_{k}^{(2)},
\end{aligned}
$$

where the inequality is true since $\theta_{k}^{l}\left(r_{k+1}\right)$ yields the maximal $W_{k}^{(2)}$. So, it is profitable to increase the inventory from $w_{k}$ to $\theta_{k}^{l}\left(r_{k+1}\right)$. However, since the amount of the expediting order is limited by $M_{k}$, we have $\theta_{k}^{*}\left(r_{k+1}\right)=\min \left\{\theta_{k}^{l}\left(r_{k+1}\right), w_{k}+M_{k}\right\}$. Note that if $w_{k} \leq-M_{k}, \theta_{k}^{*}\left(r_{k+1}\right)=w_{k}+M_{k}$.

Case II-b $\left(\theta_{k}^{l}\left(r_{k+1}\right) \leq 0\right)$. It is straightforward to show that $W_{k}^{(2)}=v_{k} w_{k}+\gamma V_{k+1}\left(0, r_{k+1}\right)=Y_{k}^{(2)}$. Consequently, it is optimal to fulfill all the backorders. However, since the amount of the expediting order is limited by $M_{k}$, we have $\theta_{k}^{*}\left(r_{k+1}\right)=\min \left\{0, w_{k}+M_{k}\right\}$.

Then, for $x_{k} \longrightarrow+\infty$, we have $x_{k}-D_{k} \geq 0$, i.e., $w_{k} \geq$ 0 . Thus, $\partial G_{k}\left(x_{k}, r_{k}\right) /\left.\partial x_{k}\right|_{x_{k} \rightarrow+\infty}$ depends on the analysis in Case I; we have

$$
\left.\frac{\partial G_{k}\left(x_{k}, r_{k}\right)}{\partial x_{k}}\right|_{x_{k} \longrightarrow+\infty}=s_{k} \geq 0,
$$

because of the concavity, $\partial V_{k}\left(x_{k}, r_{k}\right) / \partial x_{k} \geq \partial G_{k}\left(x_{k}, r_{k}\right) /$ $\left.\partial x_{k}\right|_{x_{k} \rightarrow+\infty}$. Then $\partial V_{k}\left(x_{k}, r_{k}\right) / \partial x_{k} \geq 0$. Therefore, $V_{k}\left(x_{k}, r_{k}\right)$ is increasing in $x_{k}$ for a given $r_{k}$.

Finally, we show the supermodularity of $H_{t}\left(z_{t}, w_{t}, r_{t+1}\right)$ in $\left(z_{t}, w_{t}\right)$. From (5), we only need to prove the supermodularity of $V_{t+1}\left(w_{t}-z_{t}, r_{t+1}\right)$ and the submodularity of $h_{t}\left(w_{t}-z_{t}\right)^{+}+$ $b_{t}\left(z_{t}-w_{t}\right)^{+}$in $\left(z_{t}, w_{t}\right)$. Because the concavity of $V_{t+1}\left(w_{t}-\right.$ $\left.z_{t}, r_{t+1}\right)$, it is clear that $V_{t+1}\left(w_{t}-z_{t}, r_{t+1}\right)$ is supermodular in $\left(z_{t}, w_{t}\right)$. In addition, the submodularity of $h_{t}\left(w_{t}-z_{t}\right)^{+}+$ $b_{t}\left(z_{t}-w_{t}\right)^{+}$follows from the convexity of $h_{t}(x)^{+}+b_{t}(x)^{+}$. Thus, $H_{t}\left(z_{t}, w_{t}, r_{t+1}\right)$ is supermodular in $\left(z_{t}, w_{t}\right)$.

(iv) The supermodularity of $V_{t}\left(x_{t}, r_{t}\right)$ in $\left(x_{t}, r_{t}\right)$ is also proved by induction. Starting from $t=T$, it is obvious that $V_{T+1}\left(x_{T+1}, r_{T+1}\right)$ is supermodular in $\left(x_{T+1}, r_{T+1}\right)$. Thus $J_{T}\left(y_{T}, d_{T}, r_{T}\right)$ is supermodular in $\left(x_{T}, r_{T}\right)$ since the terms in $J_{T}\left(y_{T}, d_{T}, r_{T}\right)$ are independent of $x_{T}$. Following the maximization preserves supermodularity which yields the supermodularity of $V_{T}\left(x_{T}, r_{T}\right)$ in $\left(x_{T}, r_{T}\right)$.

Assume that the result holds for $t=k+1$. Next, we need to show that the result is still true for $t=k$. Since $J_{k}\left(y_{k}, d_{k}, r_{k}\right)$ is independent of $x_{k}$, we only need to proof the supermodularity of $J_{k}\left(y_{k}, d_{k}, r_{k}\right)$ in $\left(y_{k}, r_{k}\right),\left(d_{k}, r_{k}\right)$, and $\left(y_{k}, d_{k}\right)$, which is equivalent to the supermodularity of $J_{k}\left(y_{k}, x_{k}, r_{k}\right)$ in $\left(y_{k}, x_{k}, r_{k}\right),\left(d_{k}, x_{k}, r_{k}\right)$, and $\left(y_{k}, d_{k}, x_{k}\right)$.

First, we proof the supermodularity of $J_{k}\left(y_{k}, d_{k}, r_{k}\right)$ in $\left(y_{k}, r_{k}\right)$. The terms in $J_{k}\left(y_{k}, d_{k}, r_{k}\right)$ either depends on $y_{k}$ or $r_{k}$ or is a constant with respect to $y_{k}$ and $r_{k}$ except for $V_{k+1}\left(y_{k}-\right.$ $\left.\beta_{k} d_{k}-\epsilon_{k}-z_{k}, \alpha r_{k}+(1-\alpha) p_{k}\right)$, so it suffices to show the supermodularity of $V_{k+1}\left(\mathrm{y}_{k}-\beta_{k} d_{k}-\epsilon_{k}-z_{k}, \alpha r_{k}+(1-\alpha) p_{k}\right)$ in $\left(y_{k}, r_{k}\right)$.

Consider arbitrary pair $\left(y_{k}^{1}, y_{k}^{2}\right)$ and $\left(r_{k}^{1}, r_{k}^{2}\right)$ with $y_{k}^{1}>y_{k}^{2}$ and $r_{k}^{1}>r_{k}^{2}$. Fix $\epsilon_{k}$; let

$$
\begin{aligned}
& \left(\tau_{1}, \xi_{1}\right)=\left(y_{k}^{1}-\beta_{k} d_{k}\left(p_{k}, r_{k}^{1}\right)-\epsilon_{k}, \xi_{1}\right), \\
& \left(\tau_{2}, \xi_{2}\right)=\left(y_{k}^{1}-\beta_{k} d_{k}\left(p_{k}, r_{k}^{2}\right)-\epsilon_{k}, \xi_{2}\right) \\
& \left(\tau_{3}, \xi_{1}\right)=\left(y_{k}^{2}-\beta_{k} d_{k}\left(p_{k}, r_{k}^{1}\right)-\epsilon_{k}, \xi_{1}\right), \\
& \left(\tau_{4}, \xi_{2}\right)=\left(y_{k}^{2}-\beta_{k} d_{k}\left(p_{k}, r_{k}^{2}\right)-\epsilon_{k}, \xi_{2}\right)
\end{aligned}
$$


where $\xi_{1}=\alpha r_{k}^{1}+(1-\alpha) p_{k}\left(d_{k}, r_{k}^{1}\right) ; \xi_{2}=\alpha r_{k}^{2}+(1-\alpha) p_{k}\left(d_{k}, r_{k}^{2}\right)$. Then we obviously have $\xi_{1}>\xi_{2}, \tau_{3}<\tau_{4}$. Thus, we have

$$
\begin{aligned}
V_{k+1} & \left(\tau_{1}, \xi_{1}\right)-V_{k+1}\left(\tau_{3}, \xi_{1}\right) \\
& =V_{k+1}\left(\tau_{3}+\left(y_{k}^{1}-y_{k}^{2}\right), \xi_{1}\right)-V_{k+1}\left(\tau_{3}, \xi_{1}\right) \\
& \geq V_{k+1}\left(\tau_{4}+\left(y_{k}^{1}-y_{k}^{2}\right), \xi_{1}\right)-V_{k+1}\left(\tau_{4}, \xi_{1}\right) \\
& =V_{k+1}\left(\tau_{2}, \xi_{1}\right)-V_{k+1}\left(\tau_{4}, \xi_{1}\right) \\
& \geq V_{k+1}\left(\tau_{2}, \xi_{2}\right)-V_{k+1}\left(\tau_{4}, \xi_{2}\right),
\end{aligned}
$$

where the first inequality follows from the concavity of $V_{k+1}$ and the second inequality follows from the supermodularity of $V_{k+1}(\tau, \xi)$ in $(\tau, \xi)$ by induction assumption, which implies that $V_{k+1}\left(y_{k}^{1}-\beta_{k} d_{k}-\epsilon_{k}-z_{k}, \alpha r_{k}+(1-\alpha) p_{k}\right)-V_{k+1}\left(y_{k}^{2}-\right.$ $\left.\beta_{k} d_{k}-\epsilon_{k}-z_{k}, \alpha r_{k}+(1-\alpha) p_{k}\right)$ is increasing in $r_{k}$. We thus get the supermodularity of $V_{k+1}\left(y_{k}-\beta_{k} d_{k}-\epsilon_{k}-z_{k}, \alpha r_{k}+(1-\right.$ $\left.\alpha) p_{k}\right)$ in $\left(y_{k}, r_{k}\right)$. Consequently, $J_{k}\left(y_{k}, d_{k}, r_{k}\right)$ is supermodular in $\left(y_{k}, r_{k}\right)$.

Second, the supermodularity of $J_{k}\left(y_{k}, d_{k}, r_{k}\right)$ in $\left(d_{k}, r_{k}\right)$ is similar to that of Theorem 6 in Güler et al. [15].

Third, the first two terms in (4) are supermodular in $\left(y_{k}, d_{k}\right)$ by Assumption 2. Furthermore, because $H_{t}\left(z_{t}, w_{t}, r_{t+1}\right)$ is supermodular in $\left(y_{k}, d_{k}\right)$ by the concavity of $H$. Thus, $J_{k}\left(y_{k}, d_{k}, r_{k}\right)$ is supermodular in $\left(y_{k}, d_{k}\right)$.

In summary, $J_{k}\left(y_{k}, d_{k}, r_{k}\right)$ is supermodular in $\left(x_{k}, r_{k}\right)$. Therefore, $V_{k}\left(x_{k}, r_{k}\right)$ is supermodular in $\left(x_{k}, r_{k}\right)$. This completes the proof.

Proof of Theorem 4. (i) From (8), according to Assumption 2 and Theorem $3, d_{t} \cdot p_{t}\left(d_{t}, r_{t}\right)$ and $H_{t}\left(z_{t}, w_{t}, r_{t+1}\right)$ are concave, together with the concavity preserves by maximization yield the concavity of $G_{t}\left(y_{t}, r_{t}\right)$ in $\left(y_{t}, r_{t}\right)$.

(ii) By the concavity of $H_{t}\left(z_{t}, w_{t}, r_{t+1}\right)$ and supermodularity of $d_{t} \cdot p_{t}\left(d_{t}, r_{t}\right)$, we have that $-c_{t} y_{t}+G_{t}\left(y_{t}, r_{t}\right)$ is supermodular in $\left(x_{t}, y_{t}\right)$ and $\left\{\left(x_{t}, y_{t}, r_{t}\right) \mid x_{t} \leq y_{t} \leq x_{t}+\right.$ $\left.Q_{t}, p \leq r_{t} \leq \bar{p}\right\}$ is a lattice in $\left(x_{t}, y_{t}, r_{t}\right)$; thus $y_{t}^{*}\left(x_{t}, r_{t}\right)$ is increasing in $x_{t}$ by Theorem 2.2.8 in Simchi-Levi et al. [50].

Note that $q_{t}^{*}\left(x_{t}, r_{\mathrm{t}}\right)$ is given by

$$
q_{t}^{*}\left(x_{t}, r_{t}\right)=\arg \max _{0 \leq q_{t} \leq Q_{t}}\left\{-c_{t} q_{t}+G_{t}\left(x_{t}+q_{t}, r_{t}\right)\right\} .
$$

By the concavity of $G_{t},-c_{t} y_{t}+G_{t}\left(x_{t}+q_{t}, r_{t}\right)$ is submodular in $\left(x_{t}, q_{t}\right)$, because $\left\{\left(x_{t}, q_{t}, r_{t}\right) \mid 0 \leq q_{t} \leq Q_{t}, p \leq r_{t} \leq \bar{p}\right\}$ is a lattice in $\left(x_{t}, q_{t}, r_{t}\right)$, we obtain that $q_{t}^{*}\left(x_{t}, r_{t}\right)$ is decreasing in $x_{t}$.

(iii) Since $J_{t}\left(y_{t}, d_{t}, r_{t}\right)$ is joint concave in $\left(y_{t}, d_{t}, r_{t}\right)$, we first rewrite (3) as

$$
\begin{aligned}
& V_{t}\left(x_{t}, r_{t}\right)=\max _{\underline{d}_{t} \leq d_{t} \leq \bar{d}_{t}} \mathrm{E}\left\{d_{t} \cdot p_{t}\left(d_{t}, r_{t}\right)+c_{t} x_{t}\right. \\
& \quad+\max _{x_{t} \leq y_{t} \leq x_{t}+\mathrm{Q}_{t}}\left[-c_{t} y_{t}\right. \\
& \left.\left.\quad+\widetilde{G}_{t}\left(y_{t}-\beta_{t} d_{t}-\epsilon_{t}, \alpha r_{t}+(1-\alpha) p_{t}\left(d_{t}, r_{t}\right)\right)\right]\right\},
\end{aligned}
$$

\section{References}

[1] H. Helson and W. Bevan, "An investigation of variables in judgments of relative area," Journal of Experimental Psychology,

vol. 67 , no. 4 , pp. 335-341, 1964.

$$
\begin{aligned}
\widetilde{G}_{t} & \left(y_{t}-\beta_{t} d_{t}-\epsilon_{t}, \alpha r_{t}+(1-\alpha) p_{t}\left(d_{t}, r_{t}\right)\right) \\
& =\max _{-M_{t} \leq z_{t}} H_{t}\left(z_{t}, y_{t}-\beta_{t} d_{t}-\epsilon_{t}, \alpha r_{t}\right. \\
& \left.+(1-\alpha) p_{t}\left(d_{t}, r_{t}\right)\right) .
\end{aligned}
$$

To see $d_{t}^{*}\left(x_{t}, r_{t}\right)$ is increasing in $x_{t}$, we only need to verify the supermodularity of function $d_{t} \cdot p_{t}\left(d_{t}, r_{t}\right)+c_{t} x_{t}+$ $\max _{x_{t} \leq y_{t} \leq x_{t}+Q_{t}}\left[-c_{t} y_{t}+\widetilde{G}_{t}\left(y_{t}-\beta_{t} d_{t}-\epsilon_{t}, \alpha r_{t}+(1-\alpha) p_{t}\left(d_{t}, r_{t}\right)\right)\right]$ in $\left(x_{t}, d_{t}\right)$. Because the first two terms are supermodular according to Assumption 2, it suffices to show the supermodularity of

$$
\begin{aligned}
& g_{t}\left(x_{t}, d_{t}, r_{t}\right)=\max _{x_{t} \leq y_{t} \leq x_{t}+Q_{t}} \mathrm{E}\left[-c_{t} y_{t}\right. \\
& \left.\quad+\widetilde{G}_{t}\left(y_{t}-\beta_{t} d_{t}-\epsilon_{t}, \alpha r_{t}+(1-\alpha) p_{t}\left(d_{t}, r_{t}\right)\right)\right],
\end{aligned}
$$

in $\left(x_{t}, d_{t}\right)$. Follows from the fact that $V_{t}$ and $\alpha r_{t}+$ $(1-\alpha) p_{t}\left(d_{t}, r_{t}\right)$ are increasing in $r_{t}$ by Theorem 7 and Assumption 1, respectively, we have that $H_{t}\left(z_{t}, y_{t}-\beta_{t} d_{t}-\right.$ $\left.\epsilon_{t}, \alpha r_{t}+(1-\alpha) p_{t}\left(d_{t}, r_{t}\right)\right)$ is increasing in $r_{t}$. This, together with the concavity of $\widetilde{G}_{t}$, we can show the supermodularity of $\widetilde{G}_{t}\left(y_{t}-\beta_{t} d_{t}-\epsilon_{t}, \alpha r_{t}+(1-\alpha) p_{t}\left(d_{t}, r_{t}\right)\right)$ in $\left(d_{t}, r_{t}\right)$ similarly to the proof of Theorem 6 in Güler et al. [15]. Therefore, $-c_{t} y_{t}+\widetilde{G}_{t}\left(y_{t}-\beta_{t} d_{t}-\epsilon_{t}, \alpha r_{t}+(1-\alpha) p_{t}\left(d_{t}, r_{t}\right)\right)$ is supermodular in $\left(x_{t}, d_{t}, r_{t}\right)$ since it is independent of $x_{t}$. Taking expectation over $\beta_{t}$ and $\epsilon_{t}$ preserves supermodularity and $\left\{\left(x_{t}, y_{t}, d_{t}, r_{t}\right) \mid\right.$ $\left.x_{t} \leq y_{t} \leq x_{t}+Q_{t}, p \leq r_{t} \leq \bar{p}\right\}$ is a lattice in $\left(x_{t}, y_{t}, d_{t}, r_{t}\right)$, then $g_{t}\left(x_{t}, d_{t}, r_{t}\right)$ is supermodular in $\left(x_{t}, d_{t}\right)$. By Theorem 2.2.8 in Simchi-Levi et al. [50], $d_{t}^{*}\left(x_{t}, r_{t}\right)$ is increasing in $x_{t}$. Finally, since $p_{t}\left(d_{t}, r_{t}\right)$ is decreasing in $d_{t}$, then $p_{t}^{*}\left(x_{t}, r_{t}\right)$ is decreasing in $x_{t}$.

(iv) Since $H_{t}\left(z_{t}, w_{t}, r_{t+1}\right)$ is supermodular in $\left(z_{t}, w_{t}\right)$ by Theorem 3 and $\left\{\left(z_{t}, w_{t}, r_{t+1}\right) \mid-M_{t} \leq z_{t} \leq\left(w_{t}\right)^{+}, \underline{p} \leq\right.$ $\left.r_{t+1} \leq \bar{p}\right\}$ is a lattice in $\left(z_{t}, w_{t}, r_{t+1}\right)$, we obtain that $z_{t}^{*}\left(w_{t}, \bar{r}_{t+1}\right)$ is increasing in $w_{t}$ by Theorem 2.2.8 in Simchi-Levi et al. [50].

\section{Data Availability}

We did not use data in our research but programmed our results by using MATLAB 2014 to simulate the results of our research. If necessary, we can provide the Matlab source code.

\section{Conflicts of Interest}

The authors declare that they have no conflicts of interest.

\section{Acknowledgments}

This work was supported by the National Natural Science Foundation of China (Grant no. 71071134). 
[2] D. Kahneman and A. Tversky, "Prospect theory: an a nalysis of decision under risk," Econometrica, vol. 47, no. 2, pp. 263-292, 1979.

[3] G. Kalyanaram and R. S. Winer, "Empirical generalizations from reference price research," Marketing Science, vol. 14, no. 3, pp. G161-G169, 1995.

[4] C. Mathies and S. Gudergan, "Revenue management and customer centric marketing - How do they influence travellers' choices?" Journal of Revenue and Pricing Management, vol. 6, no. 4, pp. 331-346, 2007.

[5] Q. Feng, "Integrating dynamic pricing and replenishment decisions under supply capacity uncertainty," Management Science, vol. 56, no. 12, pp. 2154-2172, 2010.

[6] F. Grosvenor and T. A. Austin, "Ciscos eHub initiative," Supply Chain Management Review, pp. 28-35, 2001.

[7] R. L. Cook, B. Gibson, and D. MacCurdy, "A lean approach to cross docking," Supply Chain Management Review, pp. 54-59, 2005.

[8] J. P. Cederlund, K. Rajiv, S. A. Sherer, and Y. Yao, "How Motorola put CPFR into action," Supply Chain Management Review, pp. 28-35, 2007.

[9] S. X. Zhu, "Joint pricing and inventory replenishment decisions with returns and expediting," European Journal of Operational Research, vol. 216, no. 1, pp. 105-112, 2012.

[10] K. Fu, J. Xu, and Z. Miao, "Newsvendor with multiple options of expediting," European Journal of Operational Research, vol. 226, no. 1, pp. 94-99, 2013.

[11] S. X. Zhou and X. Chao, "Dynamic pricing and inventory management with regular and expedited supplies," Production Engineering Research and Development, vol. 23, no. 1, pp. 65-80, 2014.

[12] M. S. Roni, M. Jin, and S. D. Eksioglu, "A hybrid inventory management system responding to regular demand and surge demand," OMEGA, vol. 52, pp. 190-200, 2015.

[13] X. Li, Z. Lian, K. K. Choong, and X. Liu, "A quantity-flexibility contract with coordination," International Journal of Production Economics, vol. 179, pp. 273-284, 2016.

[14] M. G. Güler, T. Bilgiç, and R. Güllü, "Joint inventory and pricing decisions with reference effects," Institute of Industrial Engineers (IIE). IIE Transactions, vol. 46, no. 4, pp. 330-343, 2014.

[15] M. G. Güler, T. Bilgiç, and R. Güllü, "Joint pricing and inventory control for additive demand models with reference effects," Annals of Operations Research, vol. 226, no. 1, pp. 255-276, 2015.

[16] S. Wu, Q. Liu, and R. Q. Zhang, "The reference effects on a retailer's dynamic pricing and inventory strategies with strategic consumers," Operations Research, vol. 63, no. 6, pp. 1320-1335, 2015.

[17] X. Chen, P. Hu, S. Shum, and Y. Zhang, "Dynamic stochastic inventory management with reference price effects," Operations Research, vol. 64, no. 6, pp. 1529-1536, 2016.

[18] G. D. Eppen and A. V. Iyer, "Improved fashion buying with bayesian updates," Operations Research, vol. 45, no. 6, pp. 805819, 1997.

[19] M. Henig, Y. Gerchak, R. Ernst, and D. F. Pyke, "An inventory model embedded in designing a supply contract," Management Science, vol. 43, no. 2, pp. 184-189, 1997.

[20] A. A. Tsay and W. S. Lovejoy, "Quantity flexibility contracts and supply chain performance," Manufacturing and Service Operations Management, vol. 1, no. 2, pp. 89-111, 1999.

[21] S. P. Sethi, H. Yan, and H. Zhang, "Quantity flexibility contracts: Optimal decisions with information updates," Decision Sciences, vol. 35, no. 4, pp. 691-712, 2004.
[22] A. Ben-Tal, B. Golany, A. Nemirovski, and J.-P. Vial, "Retailersupplier flexible commitments contracts: a robust optimization approach," Manufacturing and Service Operations Management, vol. 7, no. 3, pp. 248-271, 2005.

[23] E. A. Feinberg and M. E. Lewis, "Optimality of four-threshold policies in inventory systems with customer returns and borrowing/storage options," Probability in the Engineering and Informational Sciences, vol. 19, no. 1, pp. 45-71, 2005.

[24] R. Yin and K. Rajaram, "Joint pricing and inventory control with a Markovian demand model," European Journal of Operational Research, vol. 182, no. 1, pp. 113-126, 2007.

[25] Z. Lian and A. Deshmukh, "Analysis of supply contracts with quantity flexibility," European Journal of Operational Research, vol. 196, no. 2, pp. 526-533, 2009.

[26] K. Fu, V. N. Hsu, and C. Lee, "Note optimal component acquisition for a single-product, single-demand assemble-to-order problem with expediting," Manufacturing and Service Operations Management, vol. 11, no. 2, pp. 229-236, 2009.

[27] X. Chen, S. X. Zhou, and Y. Chen, "Integration of inventory and pricing decisions with costly price adjustments," Operations Research, vol. 59, no. 5, pp. 1144-1158, 2011.

[28] G. P. Cachon and R. Swinney, "Purchasing, pricing, and quick response in the presence of strategic consumers," Management Science, vol. 55, no. 3, pp. 497-511, 2009.

[29] G. P. Cachon and R. Swinney, "The value of fast fashion: quick response, enhanced design, and strategic consumer behavior," Management Science, vol. 57, no. 4, pp. 778-795, 2011.

[30] M. Yao and S. Minner, "Review of multi-supplier inventory models in supply chain management: an update," Working Paper, Technische Universität München, Germany, 2017.

[31] L. Krishnamurthi, T. Mazumdar, and S. P. Raj, "Asymmetric response to price in consumer brand choice and purchase quantity decisions," Journal of Consumer Research, vol. 19, no. 3, pp. 387-400, 1992.

[32] E. A. Greenleaf, "The impact of reference price effects on the profitability of price promotions," Marketing Science, vol. 14, no. 1, pp. 82-104, 1995.

[33] P. K. Kopalle, A. G. Rao, and J. L. Assunção, "Asymmetric reference price effects and dynamic pricing policies," Marketing Science, vol. 15, no. 1, pp. 60-85, 1996.

[34] G. Fibich, A. Gavious, and O. Lowengart, "Explicit solutions of optimization models and differential games with nonsmooth (asymmetric) reference-price effects," Operations Research, vol. 51, no. 5, pp. 721-734, 2003.

[35] G. Fibich, A. Gavious, and O. Lowengart, "The dynamics of price elasticity of demand in the presence of reference price effects," Journal of the Academy of Marketing Science, vol. 33, no. 1, pp. 66-78, 2005.

[36] I. Popescu and Y. Wu, "Dynamic pricing strategies with reference effects," Operations Research, vol. 55, no. 3, pp. 413-429, 2007.

[37] J. Nasiry and I. Popescu, "Dynamic pricing with loss-averse consumers and peak-end anchoring," Operations Research, vol. 59, no. 6, pp. 1361-1368, 2011.

[38] X. Chen, P. Hu, and Z. Hu, "Efficient algorithms for the dynamic pricing problem with reference price effect," Management Science, vol. 63, no. 12, pp. 4389-4408, 2016.

[39] Z. Hu, X. Chen, and P. Hu, "Technical notedynamic pricing with gain-seeking reference price effects," Operations Research, vol. 64, no. 1, pp. 150-157, 2016. 
[40] H. Arslan and S. Kachani, "Dynamic pricing under consumer reference-price effects," in Wiley Encyclopedia of Operations Research and Management Science, pp. 1-17, 2010.

[41] T. Mazumdar, S. P. Raj, and I. Sinha, "Reference price research: review and propositions," Journal of Marketing, vol. 69, no. 4, pp. 84-102, 2005.

[42] L. Gimpl-Heersink, C. Rudloff, M. Fleischmann, and A. Taudes, "Integrating Pricing and Inventory Control: Is it Worth the Effort?” Business Research, vol. 1, no. 1, pp. 106-123, 2008.

[43] L. Gimpl-Heersink, Joint pricing and inventory control under reference price effects [PhD Thesis], Vienna University of Economics and Business Administration, Vienna, Austria, 2008.

[44] T. L. Urban, "Coordinating pricing and inventory decisions under reference price effects," International Journal of Manufacturing Technology and Management, vol. 13, no. 1, pp. 78-94, 2008.

[45] Y. Zhang, Essays on robust optimization, integrated inventory and pricing, and reference price effect [PhD Thesis], University of Illinois at Urbana-Champaign, 2010.

[46] A. Taudes and C. Rudloff, "Integrating inventory control and a price change in the presence of reference price effects: a twoperiod model," Mathematical Methods of Operations Research, vol. 75, no. 1, pp. 29-65, 2012.

[47] M. G. Güler, "The value of modeling with reference effects in stochastic inventory and pricing problems," Expert Systems with Applications, vol. 40, no. 16, pp. 6593-6600, 2013.

[48] X. Chen, P. Hu, and S. He, "Technical note-Preservation of supermodularity in parametric optimization problems with nonlattice structures," Operations Research, vol. 61, no. 5, pp. 1166-1173, 2013.

[49] H. Ren and T. Huang, "Modeling customer bounded rationality in operations management: A review and research opportunities," Computers \& Operations Research, vol. 91, pp. 48-58, 2018.

[50] D. Simchi-Levi, X. Chen, and J. Bramel, The Logic of Logistics: Theory, Algorithms, and Applications for Logistics Management, Springer, New York, NY, USA, 3rd edition, 2014.

[51] D. P. Bertsekas, Dynamic Programming and Optimal Control, Athena Scientific, Nashua, NH, USA, 3rd edition, 2007. 


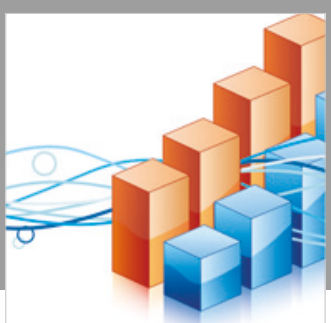

Advances in

Operations Research

\section{-n-m}
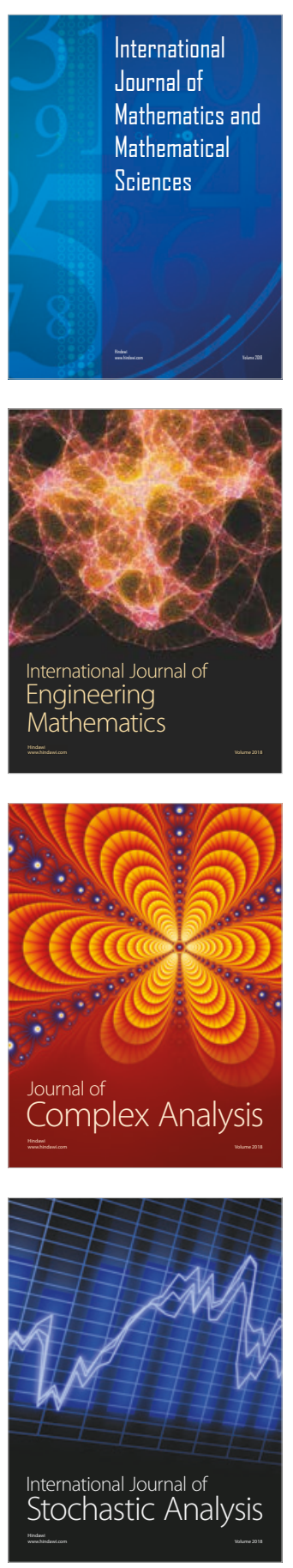
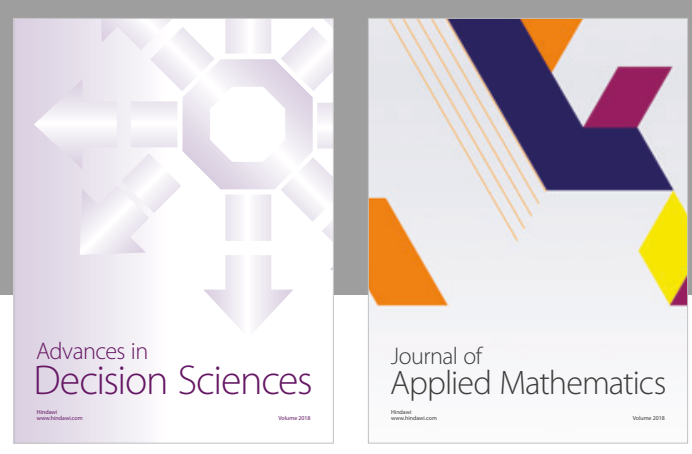

Journal of

Applied Mathematics
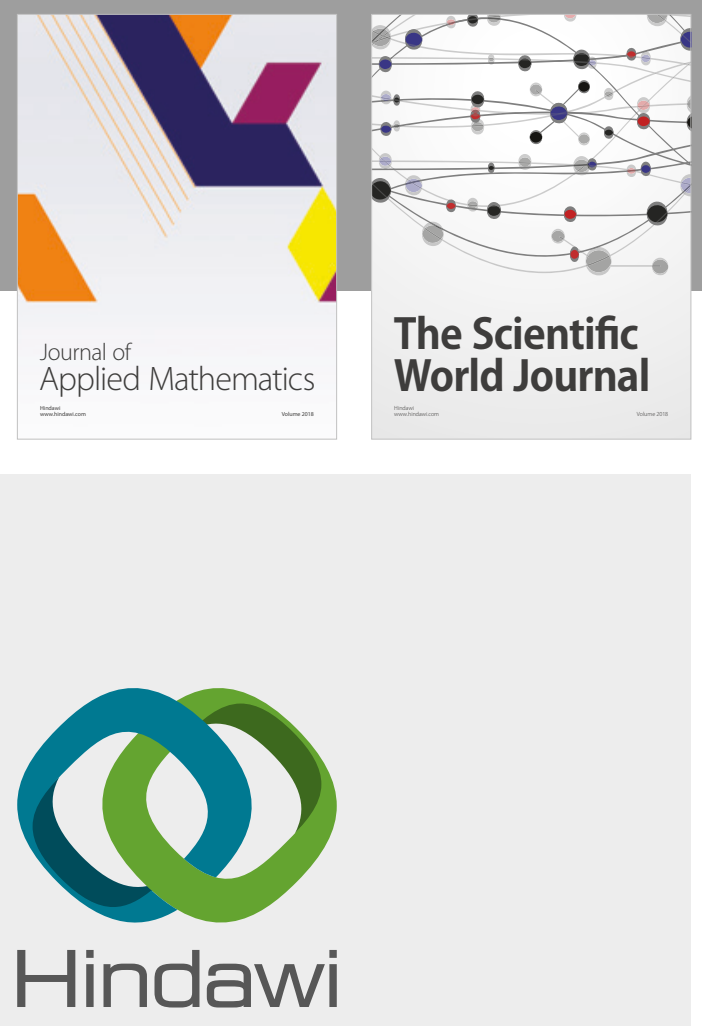

Submit your manuscripts at

www.hindawi.com

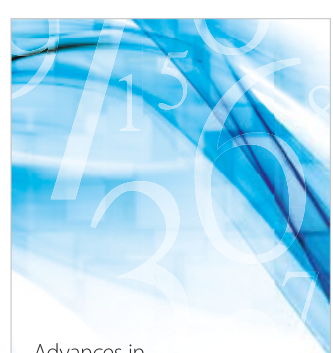

Advances in
Numerical Analysis
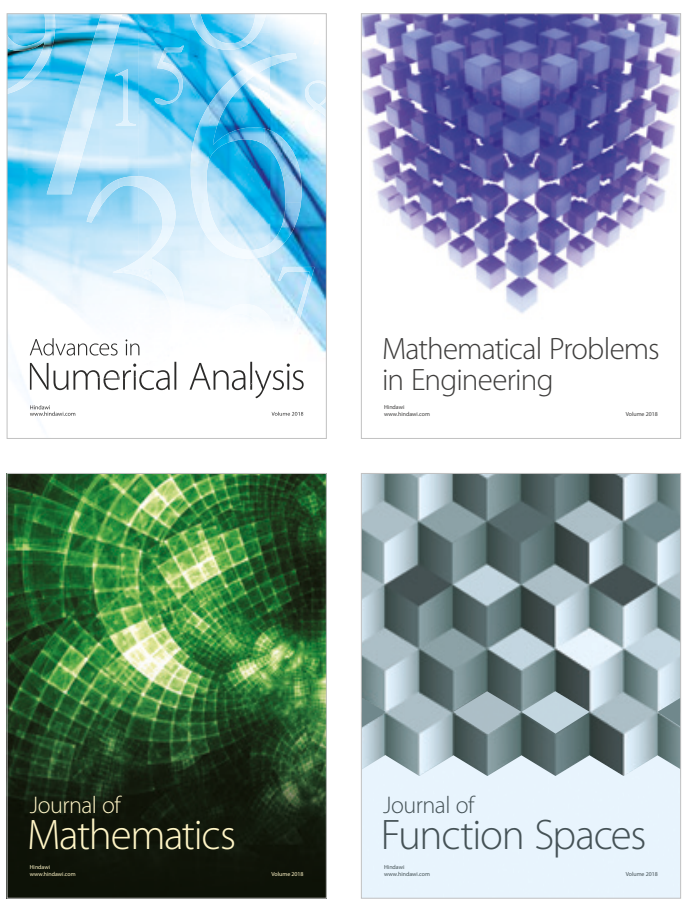

Mathematical Problems in Engineering

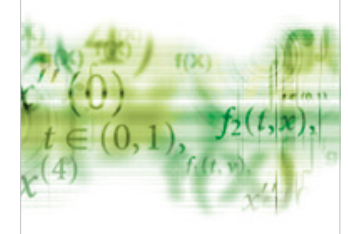

International Journal of

Differential Equations

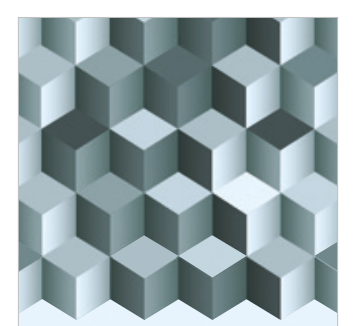

Journal of

Function Spaces

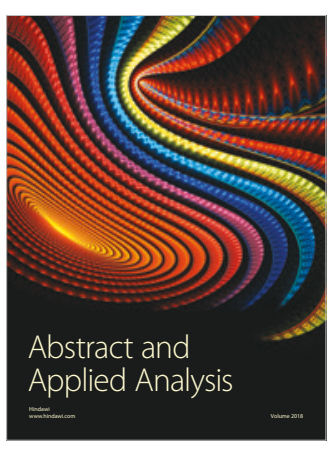

The Scientific

World Journal

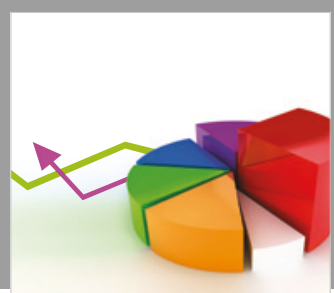

Journal of

Probability and Statistics
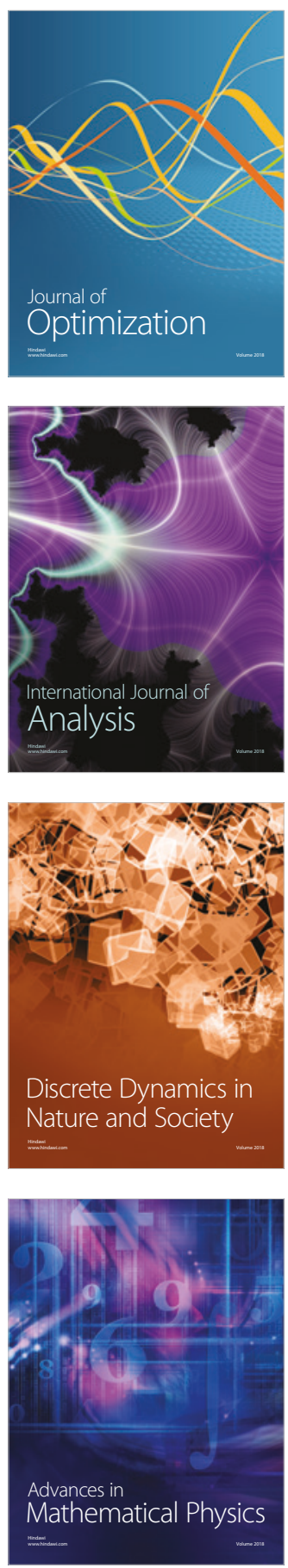